\title{
رمزية فيلم الآراجوز ودورها في ترسيخ قيم المجتمع المصري
}

(دراسة توثيقية تحليلية)

The symbolism of the movie Al-Aragoz and its role in consolidating the values of Egyptian society (Analytical documentation study)

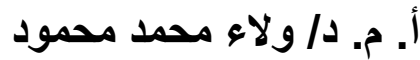

أستاذ مساعد اكاديمية الفنون- المعهل العالى للفنون الثعبية

\section{Assist. Prof. Dr. Walaa Mohamed Mahmoud \\ Assistant Professor, Academy of Arts - Higher Institute of Folklore \\ drwalaamohamed2020@gmail.com}

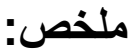

تتعدد وتتنوع الظواهر الفولكلورية وخاصة فنون الفرجة كأحد اقوى العلامات المؤثرة في تاريخ الثعوب والتي تعرض لنا صورة عن ماهية المجمعات وكيف ان لكل ظاهرة دور مؤثر وفعال بل ربما يكون دور تطويري لحياة المجتمعات و الثعوب، والفن اذ يحظى بالنصيب و القدر الاكبر في البناء المجتعي والرقى الفكري والإنساني والثقافي وليس الترفيه

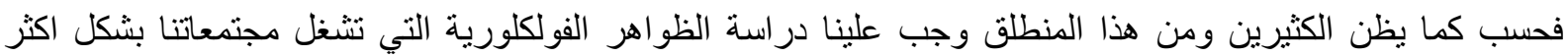
تحليلا وتفسير الما تأوله هذه الظواهر الفولكلورية المتناولة لا سيما اذ تناول الفن السينمائي احد اهم انواع الفنون تأثير التئ على البشر في كل زمان ومكان وقام بمعالجتها معالجة موضوعية عبرت عن مجتمع ما في حقبة زمانية خاصة و هذا ما فعله فيلم الاراجوز الذى عالج وناقش ما مر بالمجتمع المصري في احد اهم الحقب التاريخية في حباة هذا المجتمع ودور

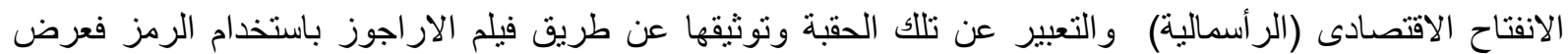
الو اقع بشكل مرموز وبناءا عليه يقوم هذا البحث على تحليل الار اجوز كأحد اهم اثكال الفرجة الشعبية وما تحظى به هذه

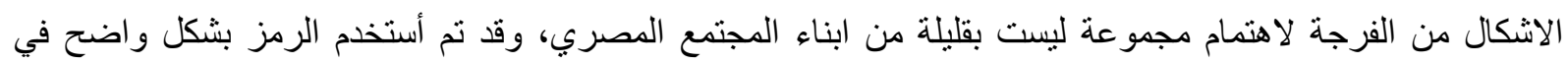
(فيلم الآراجوز) وظهر ذلك من خلال أحداث وأثخاص العمل وكيف نم الاستفادة من الاراجوز في عرض ما لم يسمح بعرضه او في التعبير عن مكنونات نفسية واحداث اجتماعية وسياسية بأثكال عدة .

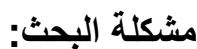

عدم وجود اعمال فنية سينمائية استخدمت اشكال الفرجة الشعبية في ترسيخ وتوثيق قيم المجتمع المصري، كما فعل فيلم الار اجوز وكذلك تتاول الكيفية التي يقوم بها الفن في معالجة الموضو عات الاجتماعية واستخدام الرمز في تلك المعالجة، كما اعرب الفيلم عن كيفية استخدام الرمز وتوظيفه من خلال الاراجوز في توثيق احد اهم الحقب التاريخية المصرية، وقد فيد انبثقت المشكلة من ذلك الربط بين الفولكلور والرمزية وكيفية نوثيق ذللك وخدمته لقيم المجتمع. الهمية البحث: التعرف على الاهمية التوثيقية التحليلية لموضوع مثل الاراجوز وكيفية عرضهه وتناوله داخل السينما وما يجب ان تكون عليه المعالجة السينمائية حيال التوثيق لمثل هذه الموضوعات ميدانيا من خلال الاعمال الفنية بما لا يخل بالعنصر الفولكلوري نفسه الا وهو الاراجوز موضوع الفيلم .

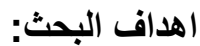
1- التعرف على الكيفية التي ممكن ان يقوم بها الار اجوز احد اشكال الفرجة الثعبية في توثثق احداث المجتمع المصري. 2- الرمز وكيفية الإسقاط الرمزي ودور ذللك في التعبير عن موضوعات الفولكلور داخل السينما . منهجية البحث: يتبع البحث المنهج الوصفي التحليلي الذى يقوم على تحليل الظاهرة الفولكلورية موضوع الدراسة بعد عمل اجر اءات وصفية لما سيتم تحليله. 


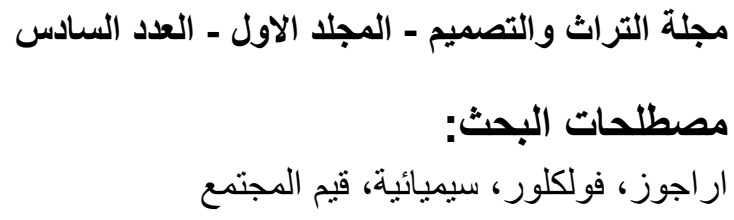

\section{Abstract:}

We can say that the frame or the image is the first unit in the film clip or the first component of the language structure or film format; It expresses the connotations and symbols through what it contains; It is the first unit to influence and persuade the viewer; This role depends on the good choice of place and time and artistic creativity in photography, directing and montage, all of which are factors that affect, especially if they carry the idea and support it and move the complex of the event to development, meaning that the cadre and its implications is considered the first unit in the formation of the cinematic sentence and it determines the internal movement of meanings according The nature of the subject, and there are several considerations that must be taken into account when composing the different scenes; It is one of the elements that make up the text and one of the elements that give the logical structure of the film in the sequence of shots and different scenes

\section{Research Problem:}

The absence of cinematic artworks that used forms of popular watching in consolidating and documenting the values of Egyptian society, as did the movie Al-Aragoz, as well as dealing with how art deals with social issues and the use of the symbol in that treatment. The film also expressed how the symbol is used and employed through Al-Aragoz in documenting One of the most important Egyptian historical periods, and the problem emerged from that linking folklore with symbolism and how to document that and serve the values of society.

The importance of the research: to identify the documentary-analytical importance of a topic such as Al-Aragoz, how it is presented and addressed in the cinema, and what the cinematic treatment should be regarding documentation of such topics in the field through artistic works, without prejudice to the folklore element itself, which is Al-Aragoz, the subject of the film.

\section{Research Aims:}

1- Getting to know how the Aragoz can do, one of the forms of popular spectacle, in documenting the events of Egyptian society.

2- The symbol and how the symbolic projection and its role in expressing the topics of folklore within the cinema.

Research Methodology: The research follows the descriptive analytical method, which is based on analyzing the folklore phenomenon under study after making descriptive procedures for what will be analyzed.

\section{Keywords:}

Argos‘semiotics,folklore, society 


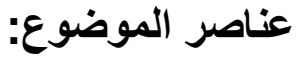

اولا: الاراجوز كأحد اشكال فنون الفرجة الثعبية ار اجوز أو القر اقوز و هناك من يسميها دمى متحركة هي كلمة ذات الصفة الصل تركي لكلمة " قره قوز " والتي تتكون من مقطعين هما " قره " بمعنى سوداء و" قوز " بمعنى عين ، وبذلك يصبح المعنى العام لكلمة " قره قوز "هو " ذو العين

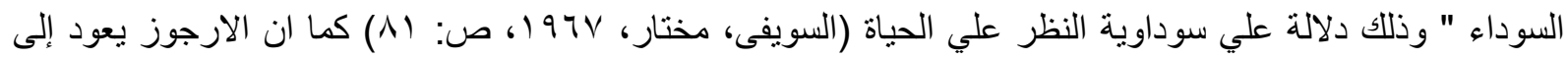

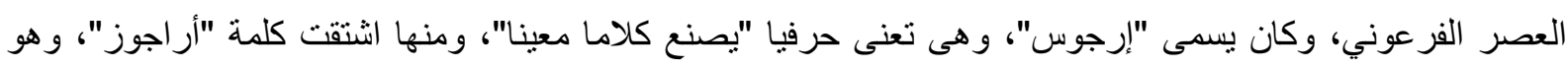
اسم يعود إلى العصر العثماني، حيث كان يسمى وقتها "قراقوز" أو "الأراجوز"، وازدهر هذا الفن الساخر في أواخر العصر المملوكي قبل الغزو العثماني، وفى العصر الحديث، كان الأراجوز سببا في ظهور مسرح العرائس الثعبي، الذى لهى تأسس عام • 19 1 على يد المونولوجست و الفنان المصري محمود شكوكو الذى كان يلقب بـ" شارلي شابلن العرب"، فكان يرتدى جلبابه وطرطوره الثهير ليقدم عروض مصاحبة مع الأراجوز، حتى افتتح مسرح العرائس الثعبي، ويعتبر مصطفى عثمان في العصر الحديث أكبر و أثشر لاعب أراجوز في مصر، وهو أحد تلاميذ الفنان القدير محمود شكوكو،

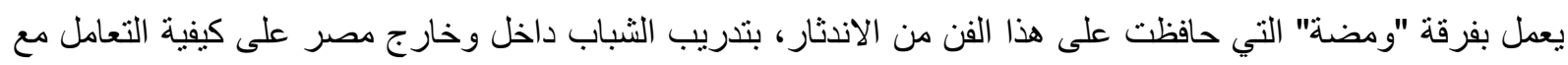

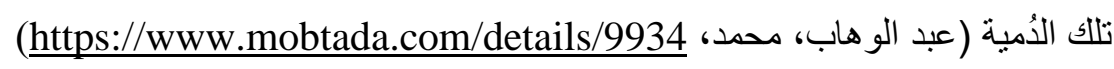
الأراجوز هو أحد الأشكال التي تنتمي لما يعرف باسم (مسرح العرائس) وهو علي وجه الدقة عبارة عن دمية قفاز، حيث نجد رأسه مصنوعة من خامة خفيفة وصلبة كالخشب ، مرسوم عليها وجه ذو تعبير ات حادة ، وتنتهي من أعلي ب "

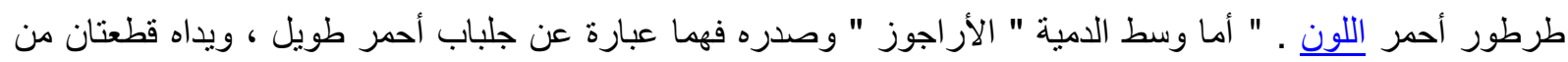
الخشب. و يتم التحكم في تحريك الدمية " الأراجوز "، عن طريق اليد حيث يستطيع اللاعب أن يحرك رأسه بأصبع

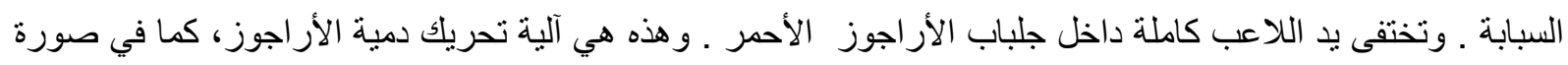

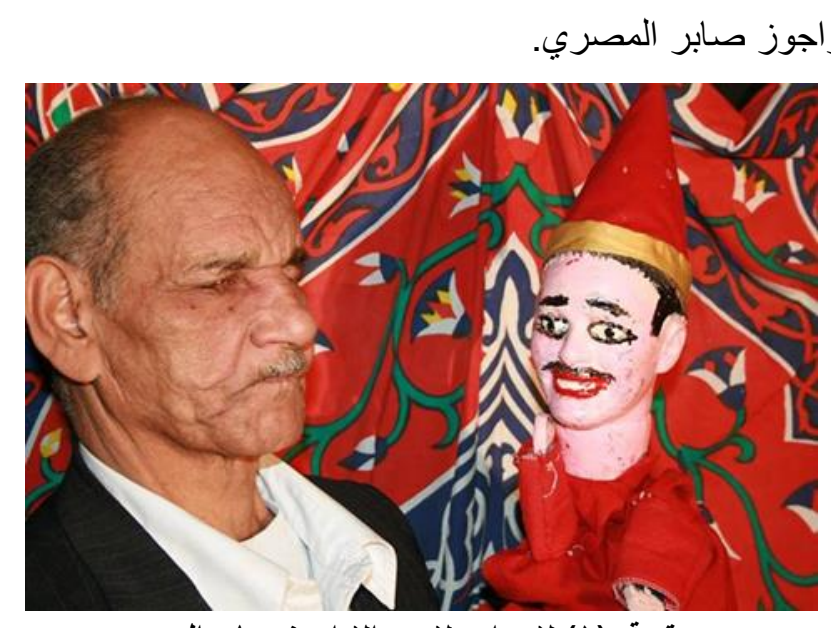

صورة رقم (1) لاحد اهم لاعبي الاراجوز صابر المصري

نصوص مسرح العرائس:

النصوص الدرامية الخاصة بمسرح الأراجوز تتنوع فبعضها يتسم بالنصية والاخر بالارتجال، حيث هنالك مجموعة من

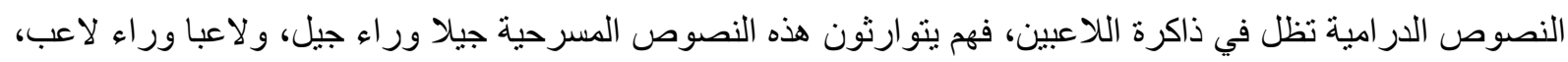
وقد يتم هذا النقل الثفاهي من أب إلي ابنه، أو من معلم إلي أحد الصبية المساعدين ـ وهذا النقل يمكن أن يكون مجهول المصدر بمعنى لا يعرف اللاعب من هو مؤلف هذا النص حتي وإن تناقله مع غبره من اللاعبين. و لكن هذا الحفظ

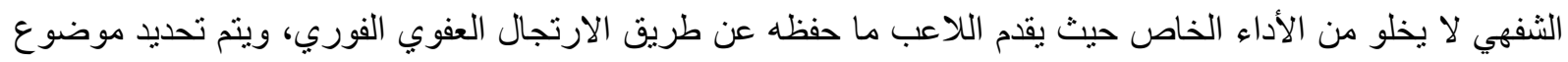

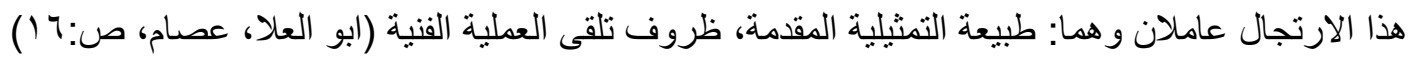


وظيفة الأداء التمثيلي للاراجوز:

ويقوم أسلوب الأداء التمثيلي في مسرح الأراجوز علي الإيحاء لا الإيهام ، فأسلوب التمثيل الايحائي يعنى بأن ما يراه

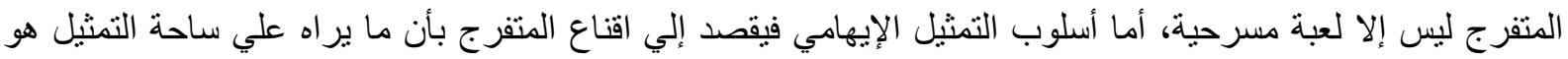
و اقع حقيقي ماثل أمام عينيه، ويعتبر اختيار أسلوب الأداء التمثيلي اختيارا منوائما مع طبيعة البنية الدرامية للنص بله المسرحي الثفاهي الذي يقده اللاعب في مسرح الأراجوز، فالنص المعروض هنا يتوجه بشكل مبانر وصريح إلي

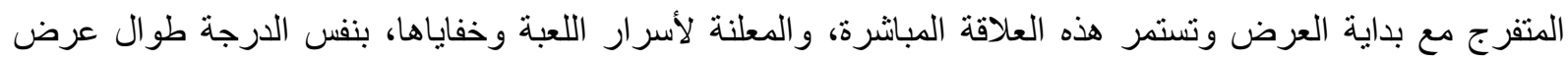
المسرحية .

و ذلك لسبيين أو لا : أن لاعب الأراجوز متمرس في أدائه ، أمي ، يجعل من مهنته حرفة يرتزق منها. ثانيا : اعنماد اللاعب علي أداة الخيال السحرية التي يمنلكها المتفرجون سواء من الصغار أو الكبار ، فهم يرون دمية فئه تتحرك وتتكلم وتقلدهم ، لذلك فإن الإطار الجمالي للأداء التمثيلي لا يتعدى أكثر من محاولة اللاعب تقليد أنماط بشرية،

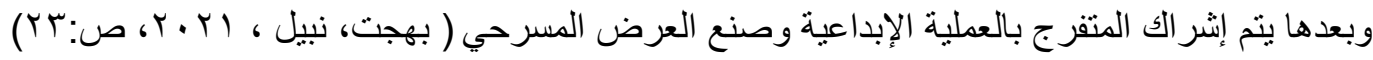
وفى عرض الاراجوز يحدث حوار بين الممثل والثانثة والثانشة والاراجوز ، و الثشاثة والجمهور، والاراجوز و الجمهور ويحرص العرض على مزج تقنيات المسرح الثعبي واعادة ابداع مفرداته حيث نرى الاراجوز بشرا ودمية خشبية (قفاز) ثم عروسة خيال و هو من شانه ان يساهم في خلق الايحاء الذى هو جوهر الاداء التمثيلي في هذه العروض

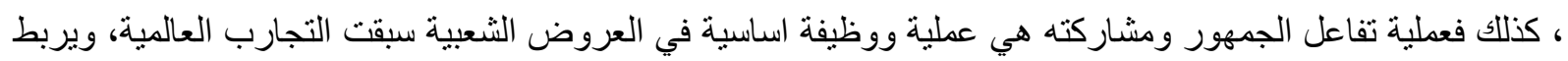
البعض بين قيم ثقافية وسياسية داخل المجتمع والبعض قام بإعادة ابداع الثخصيات فهو يرسم الثخصيات لا كما قدمناها

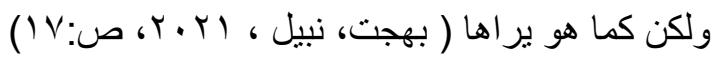
يستطر على مسرح العرائس الفكاهة واللهو حيث إن أغلب عروض مسرح الأراجوز ، عروض تنتمي إلي الطابع الملهوى ، وذلك للأسباب الأتية:

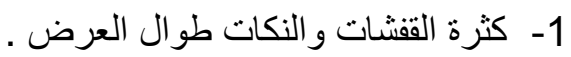
rـ البطل " الأر اجوز " يسنطيع أن ينعم بحريته بعد أن يحاول البعض و هم مثيرات الصر اع الدرامي في هذه التمثيليات

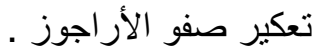
r- تنتهي أغلب التمثليات نهاية سعيدة نظر الإزاحة البطل للعقبات التي تحول دون العيش عيشة حرة . عـ الاعتماد علي مثير ات الضحك. • اللفظ وذلك كما يرد في نص " الأراجوز و الشحاذ " حينما يقول له " أنا بقي هابلغ الشوتش " حيث أن كلمة " شوتش تناسب الكلاب و لا تناسب الإنسان.

• الحركة ويتضح ذللك في اقتر اب و ابتعاد الأر اجوز من الثحاذ في الوقت الذي يطلب به الثحاذ أن يقترب منه فقط. • الموقف مثل الموقف الذي ينام فيه البربري أثناء حر اسة منزل الأراجوز ، وحين يقترب منه الأخير ويستيقظ. • الثخصية مثلا مثل شخصية الثحاذ يكاد يطلب كسرة خبز وشربة ماء ، ولكنه سرعان ما يفضح نمطه فيطلب مأكو لات معينة وكأنه سيد البيث، ونجد ذللك أيضا في نموذج الكسول الغبي " البربري " الذي يعمل حارسا وينام أثناء الحر اسة، و لا يتو الى عن ضرب سيده الأر اجوز ـ ويساعد هذا بإعلاء قيمة الضحك بالأداء التمثيلي سريع الإيقاع.

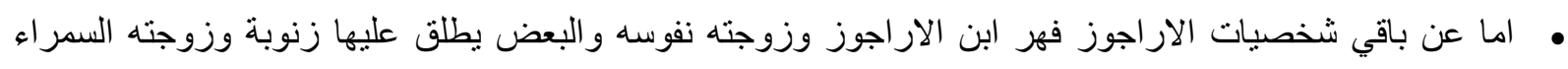
بخيته ويطلق عليها الست قمر و الفتوة وحموده الاقرع و اخوه و الاستاذ البربري و الخواجة وموشى ديان العفريت و الطبيب و الثاويش و الحانوتي و الداية و الثحات وكلب السر ايا و الزبون وو الد زوجنه و اللص. ويوجد شخصيات اخرى نسمع عنها 
ولا نر اها، ويجسد الفنان كل هذه الثخصيات بمفرده وممكن ان بستخدم دمية واحدة لذلك لتجسيد اكتر من شخصية شريطة الا يكون للامية دورين في ليلة عرض واحدة ويستخدم الفنان مجمو عة من الادوات والاكسسوارات التي تساعده على اداء

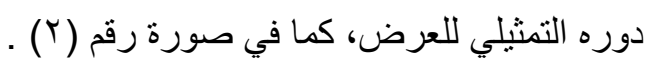

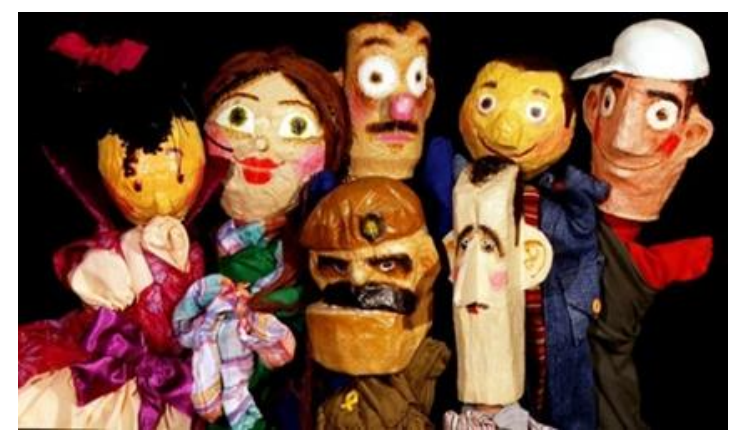

صورة رقم (r) للمجموعة من شخصيات الاراجوز

تصنع الدمى من الخشب اما بواسطة الفنان المؤدى او صانع محترف وتم استبدال العر ائس الخشبية من معظم فناني

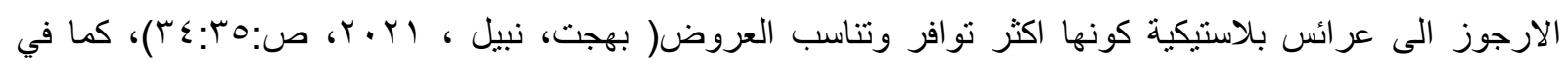

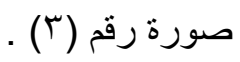

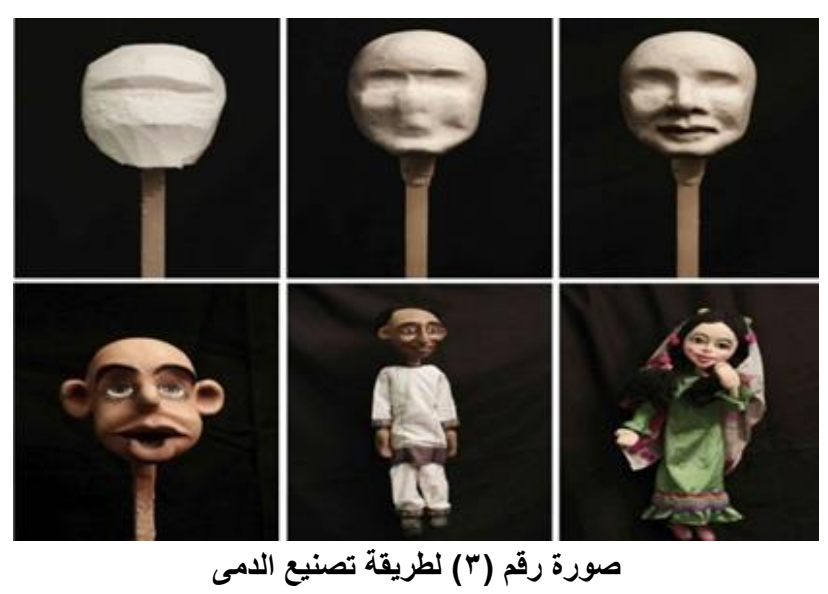

وسائط عرض الاراجوز:

هي العربة : وهى البديل الثعبي لفكرة المسرح وهى عربة من الصاج على هيئة مستطيل مسقوفة بقوائم من المعدن

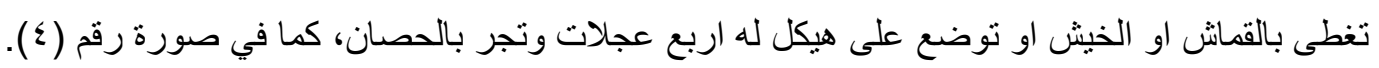

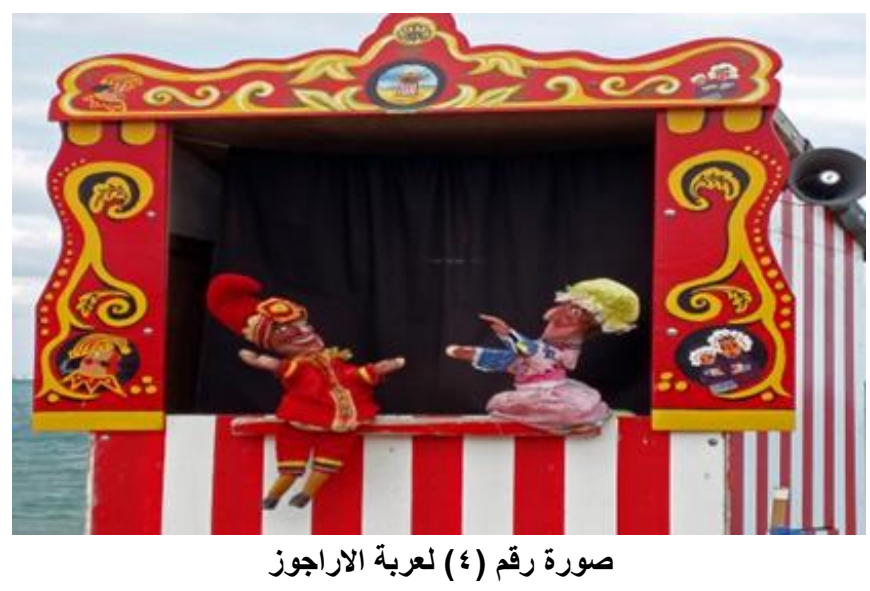


و البرفان: وهو مستطيل مكون من ثمانية مستطيلات طول الواحد Vo سم وعرضه 0؛ سم ويكسى كل منها بالقماش وتجمع ويمكن طيها لتصبح قطعة واحدة، كما في صورة رقم من من (0) .

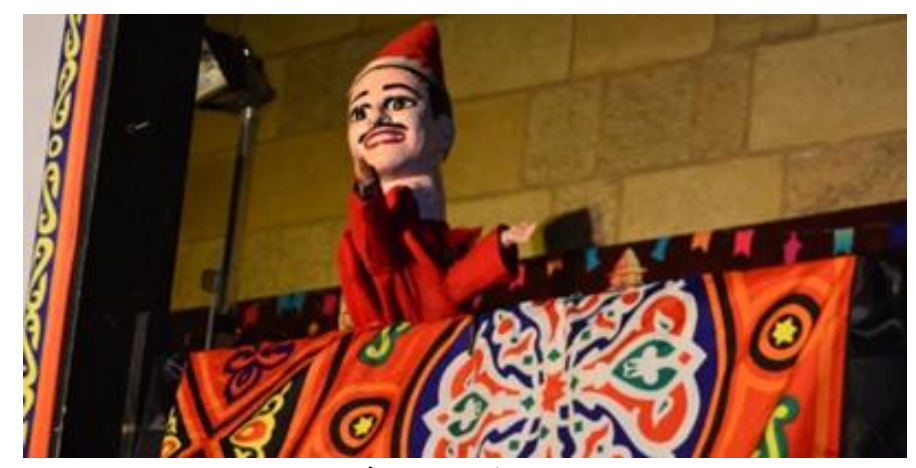

صورة رقم (0) للبرفان

و الباردة والخيمة وليس لهم وجود كبير اليوم فالخيمة كما يقول نبيل بهجت انه وجدها عند محمد كريمة وهو عبارة عن مستطيل من الخشب ويكسى بالقماش ويوضع بعرضه قطعة خشبية يصنع منها جيب يوضع فيه ولهيه الدمى اما الباردة فهي

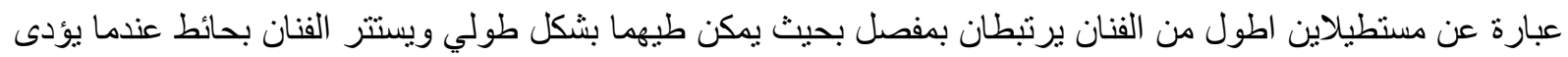

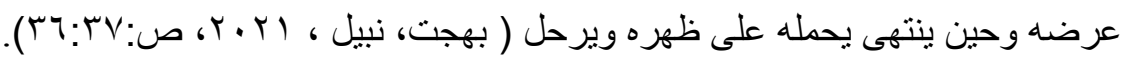
وقد قام نبيل بهجت بإعداد الملف الخاص بتسجيل موضوع الار اجوز على قائمة اليونسكو وتم اعداده اعداداً كاملاً مستفيداً من تجربة الفرقة التي احتضنت عدداً من الكنوز البشرية الحاملين لفن الأراجوز كعم صابر المصري وصدابر شيكو،

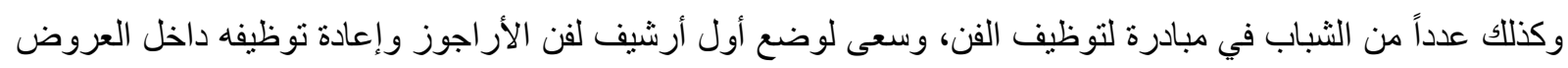

المسرحية التي تقدمها فرقة ومضة، كما في صورة رقم (؟).

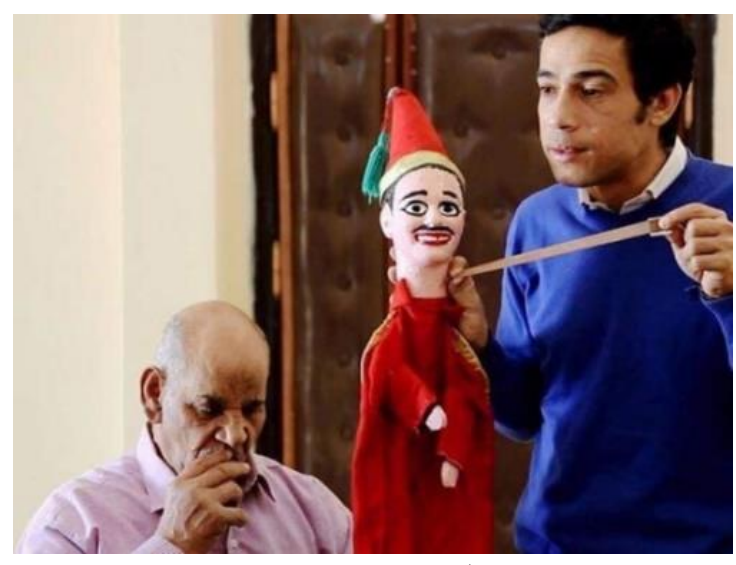

صورة رقم (T) للاكتور نبيل بهجت

وقد نظم نبيل بهجت أول مهرجان مستقل للأراجوز المصري في العديد من المر اكز الثقافية ليضع المهرجان قدميه وسط

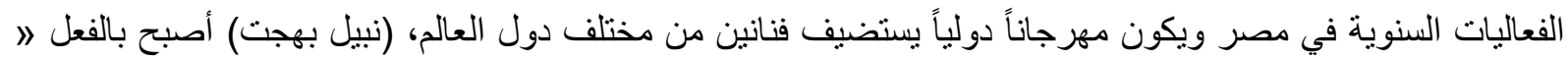
صانع الفرحه لهذا الفن الثعبي الذى كان دائما في طليعة الفنون المقاومة للاحتلال الأجنبي طو ال عقود، كما في صورة 


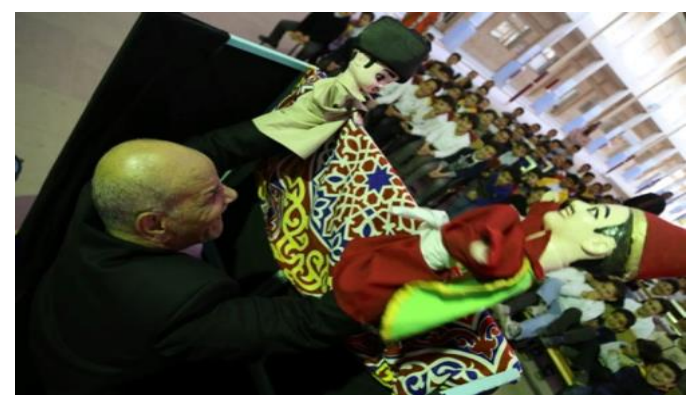

صورة رقم (V) لاحد فعاليات مهرجان الاراجوز

وكان لسان حال الثعب المصري وكان المهرجان ضروريا في إطار تنفيذ إجراءات الصون العاجل للأر اجوز المصري بعد الاعتراف به كأحد الفنون الإنسانية الهامة، وتظل ذكرى الأراجواز باقية يحمل لو اءها فرقة ومضة التي أسسها منذ

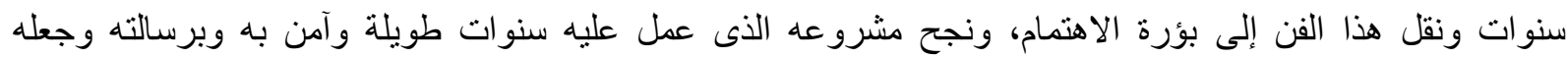
موضوعا للبحث وقد قام بنقل الأراجوز من الهامش إلى المركز ومراحل التوثيق والجمع والتأسيس والاعتر اف والإنتاج والتسجيل. رحلة نبيل بهجت مع الأراجوز تتجاوز ربع قرن لم تقتصر على جمع وتوثيق وإحياء فن الأراجوز وخيال الظل كونه مخرجا ومؤلفا مسرحيا لكنه كتب وألف ما يزيد على 17 عملا مسرحيا في مصر وخارجها حيث قدمت أعماله في مختلف دول العالم وله T معارض للتصوير الضوئي و ج معارض للعر ائس ويحتفظ مركز اطلانطا للعر ائس ب بـ عروسة من أعماله في معرض دائم بأميركا (خليفة، مؤمن https://akhbarelyom.com/news/newdetails)

\section{السيميائية ودورها في ابراز موضوعات التراث الثعبي:}

فالسينما تعتبر البداية الحقيقية لعصر الصورة عصر الإبهار العار عصر هيمنة العين عصر الفنون البصرية والثقافة البصرية

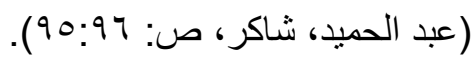
ولكى نتحدث عن الرمز كلغة سينمائية يجب اولا ان نتحدث عن الرمز والنظرية الرمزية وعلاقة الرمزية بالفيلم السينمائي؛ وكيفية ادركنا لهذا الرموز وما الفرق بين انواع الرموز المختلفة وطبيعة الرمز العالمية واستخدامه؛ وفى تهى النهاية سنطبق ذلك على أحد الأفلام التي استخدمت الرموز . نظرية الرمزية :-

هي عملية استخدام صورة محددة للتعبير عن أفكار مجردة وعواطف ليس بوصفها مباشرة ولا بشرحها من خلال مقارنات صريحة وبصور ملموسة، ولكن بالتلميح الى ما يمكن ان تكون عليه صورة الواقع المناسب، لهذه الأفكار و العو اطف وذللك بإعادة خلقها في ذهن القارئ أو المشاهد من خلال استخدام رموز غير مشروحة طبعا لطبيعة الموضوع

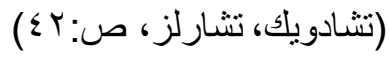
كذللك تعرف الرمزية على انها من أصل الكلمة Sumbolein في اللغة اليونانية وهى مؤلفة من Sumو ومع كلمة بمعنى حرز، ولهذه الكلمة تاريخ طويل في العلم وتترادف كلمة Sumbolein مع كلمة symbol مع كلمة creed التي تعنى دستور الايمان المسيحي "؛ كما انها تستعمل من قديم الازل في الشعائر الدينية والفنون الجميلة عموماً؛ و الثُعر بخاصة وما تزال حتى اليوم ذات قيمة اثنارية في المنطق و الرياضة و علم الدلالة اللغوية وتعريف الرمزية يمكن

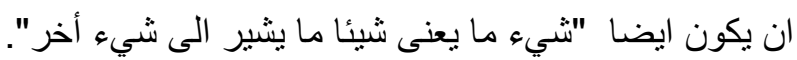
وبالنسبة للمستوى اللغوي :-

واذا ما عبرنا عن المستوى اللغوي؛ فأننا نجد أن "ريتشاردز" وجد ان هناك استخدام رمزي للكلمات بهدف تقريري " تسجيلي " واستخدام رمزي بهدف تعبيري " انفعالي " 
ليست للرمز قيمة إلا بمدى دلالته على الرغبات المكبوتة في اللاشعور نتيجة الرقابة الاجتماعية؛ الاخلاقية؛ ويفهم هذا من

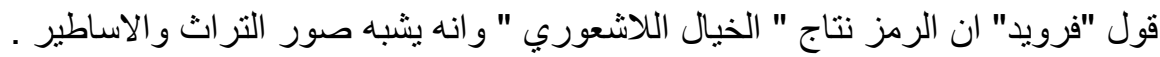

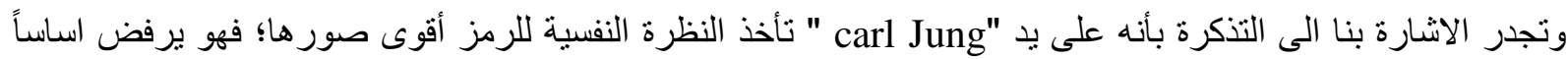
ان يكون الرمز قاصر اً على اللاشعور ؛ وكما ادعى فرويد؛ فالرمز يستمد من الشعور و اللاشعور ممتزجين, كما يفرق بين الرمز Symbol والإشارة Index؛ ذلك ان: الاشارة تعبير عن شيء معروف ومعالمه محددة في وضوح, فالملابس الخاصة بموظفي القطارات اشـارة index وليست رمزاً إذ ان الرمز افضل طريقة للإفضاء بما لا يمكن التعبير عنه فهو لا يعبر فقط عن شيء مادى هو ظاهر وواضح بل يعبر أكثر عن كل شيء له علاقة بالغموض و عدم الافصاح ( فتوح

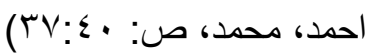
وللرمزية عدة تعريفات مثل:" هنرى دى ديجنير" "الذي قال: ان الرمز هو المقارنة بين المجرد و الملموس؛ حيث ان أحد

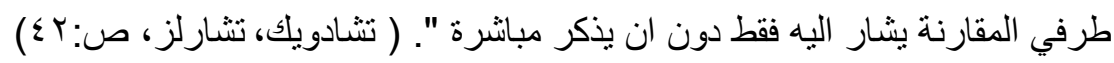

الرموز والتفكير البصرى:الرمز في اللغة يعنى الإيماء أو الإشارة والعلامة؛ ويكون ذلك بالعين والثفتتين أو الحاجبين أو أي أجزاء الجسم أو أي شكل من أثنكال التعبير اللفظبة او غير اللفظية. و الرموز عند "يونج" نو اتج طبيعية و عضوية؛ كالأحلام و الأحلام و الرموز تحدث بعفوية؛ و لا تصطنع؛ والاحلام عنده هي المدخل الرئيسي لكل معرفتنا عن الرمزية و الرمز أهم من الإشارة. يتمكن العقل البشرى من خلال الرموز من أضفاء المعنى ومن استخلاص المعاني؛ أيضا على المعلومات المتناثرة و المبعثرة والأثياء المتباعدة؛ ولذلك فأن الرموز هي وسائل لأحداث العلاقات بين ما هو موجود داخل الأنسان؛ وما هو موجود خارجه بين العالم الطبيعي و العالم الإنساني بين العالم المحدد والعالم اللامحدود بين الكون الصغير والكون الكبير. وتعمل الرموز على توسع مجالات الخبرة الإنسانية؛ وتوسع الحدود التي يمكن للحواس ان تتحرك فيها وتفتح بو ابات هائلة

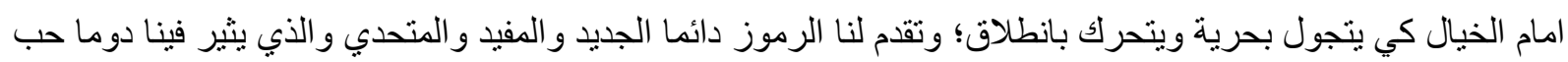
الاسنطلاع و الفضول المعرفي و الرغبة في الاستكثاف و الاستطلاع. وتختلف العلامات عن الرموز في أن الانسان؛ بالرموز قد خرج من الدائرة البيولوجية الضيقة التي تقتصر على العلامة الى الدائرة الانسانية الاوسع التي تشتمل على الرموز؛ حيث ان العلامة تعمل على الاعلان عن وجود معين او حضور موضوع ما او كائن ما او حالة ما؛ اما الرموز فأنها تعمل على احضار الصورة او الحالة الخاصة بهذا الموضوع او اوني

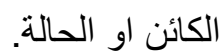

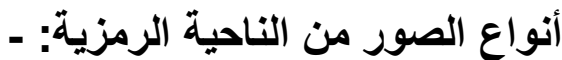

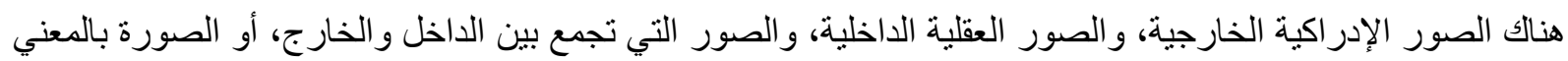
التقني و الآلي. الصورة البصرية: وهي أكثر الاستخدامات (الملموسة) (الحسوسة) وهي انعكاس موضوع ما، على مرآة، أو على عدسات، أو على غير ذلك من الأدوات البصرية، وهنا نتحدث عن الصورة بشكلها التقريبي لثنئ ما ينعكس على شبكة العين عندما ينكسر الضوء على جهاز الإبصار بشكل مناسب. 
الصورة بوصفها: تعبيراً عن التمثيل العقلي للخبرة الحسية أو إعادتها مرة أخري، باعتبار ها تمثيلاً عقلياً لخبرة سابقة، ويكون هذا التمثيل بمنزلة النسخة الأخرى لهذه الخبرة وتعد هذه النسخة أقل حيوية من الخبرة الحسية، ولكنها نظل قابلة للتعرف عليها و إدر اكها بوصفها مكوناً من مكونات الذاكرة الخاصة بهذه الخبرة. الصورة الذهنية: والني هي فى درجة أعلي من مجرد إعادة البناء للخبرة الحسية، ومع تثابه هذا الاستخدام مع كثير من

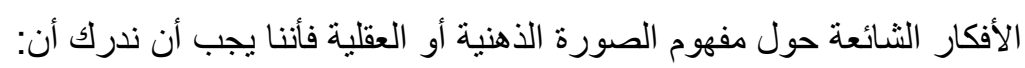

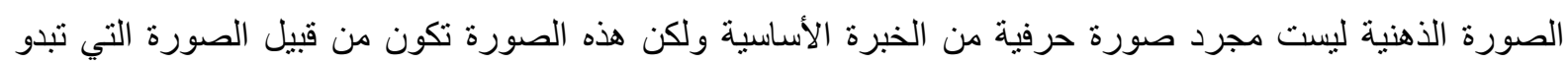
"كما لو كانت" هي الصورة الأصلية، أي أن التفكير بالصور هو عملية تنشط (صورة ذهنية) ممائلة للمشهد الخاص هن الموجود في العالم الواقعي. الصورة هنا لم يعد تتظر إليها باعتبارها مجرد إعادة إنتاج لواقعة او حادثة، ولكن باعتبار ها تتضمن عمليات بناء

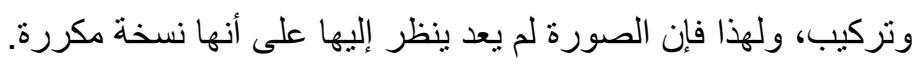

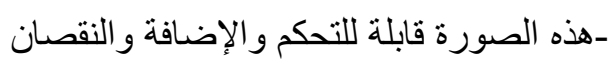
ـهذه الصورة الذهنية لبست مقصورة على التمثيلات البصرية فقط؛ ولكن أيضاً على صور سمعية أو لمسية أو فى بعض

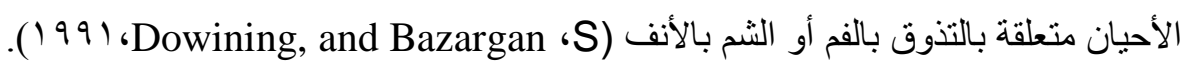

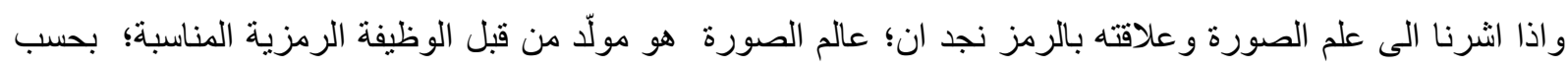

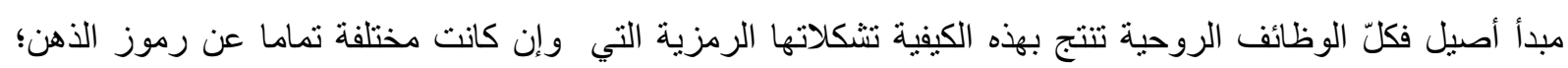
فإنها لا تختلف عنها من حيث قيمة مصدر ها الروحي، إذ لا يمكن اختزال ولا واحدة من هذه التشكلات في الأخرى فكلّ ونّ

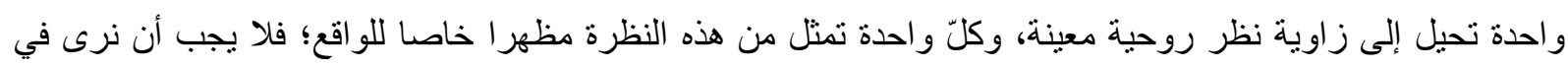

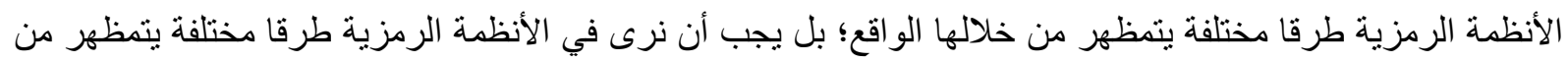

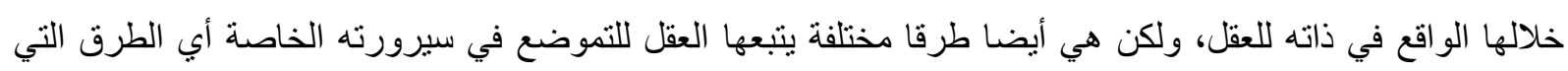
يتبعها العقل في تمظهره لذاته (http\\minerve.orglindex.php)

ادراك الرمز داخل الفيلم السينمائي :- الرئي عملية ادر الك الرمز داخل الفيلم السينمائي تعتمد على على الهية التفسير، و التحديد للإحساسات المنبعثة من مؤثرات حسية بعملية الإدر الك، فالإدر الك عملية تتضمن التأثير علي الأعضاء الحسية بمؤثرات معينة، ويقوم الفرد بإعطاء تفسير وتحديد لهذه المؤثرات ويعتمد تفسير الفرد لهذه المؤثرات علي طبيعة المؤثرات، و علي الفرد نفسه أثناء وقوع هذه المؤثرات عليه؛ أي أن الإدر الك يتوقف علي عو امل موجودة في الفرد نفسه، و وعوامل موجودة في البيئة، أو في طبيعة المؤثر الذي لئي

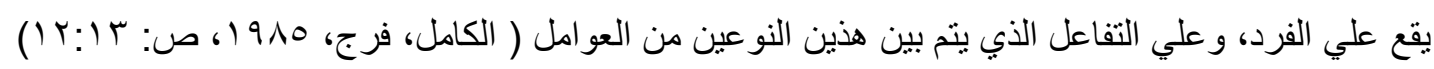
والصور في معناها الخارجي مرتبطة بالإدراك والرؤية، أي ما يحدث أمسامنا في الواقع أو على شاثشات التلبفزيون

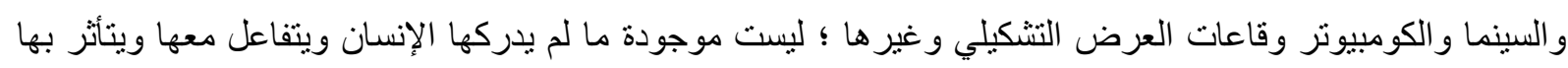
سلباً أو إيجاباً؛ فالإنسان هو الأصل و الأساس ومن دون تفاعله مع هذه الوسائط لن يكون لهذه الوسائط وجود رغم ما يقال

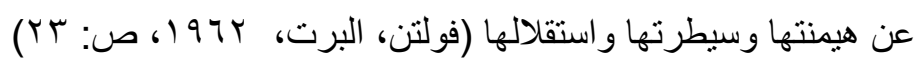
عند مشاهنتا الى فيلم سينمائي، فإننا ننظر إلى الحياة من خلال إطار صغير وليس كعالم كلى، وقد يكون لكل شيء داخل

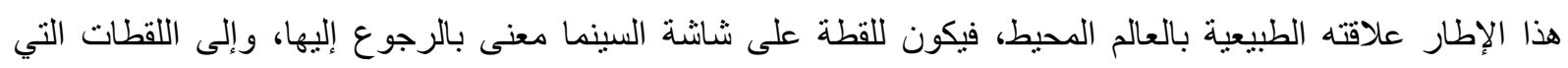
سبقتها وتلتها كمرجع، ولا يدرك المتفرج المشهد الأكبر الذى جاءت منه اللقطات؛ و هنا تبرز مهمة صانع الفيلم في اختيار 
الرموز داخل الفيلم السينمائي؛ وعلاقة تلك الرموز بالتعبير عن الصور المتحركة، والأصوات من الحياة ولفت النظر اليهم بطريقة عملية ووضعهم معا في كل سينمائي يسمي الفيلم السينمائية. وكلمة إدراك تعنى فلك الرموز؛ فالعقل يقوم بتنظيم المعلومات المرسلة إليه ووضعها في أنماط معينة والاستفادة منها، فمن المعروف أن العقل يقوم باختيار معلومات معينة، في الوقت الذي يقوم فيه بإهمال غيرها؛ ويقوم بذللك بناء علي ما هو

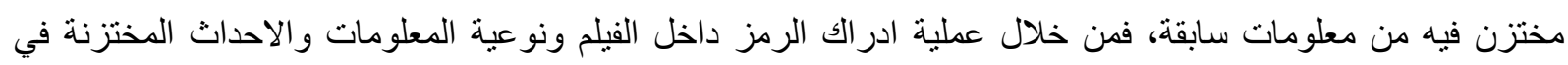

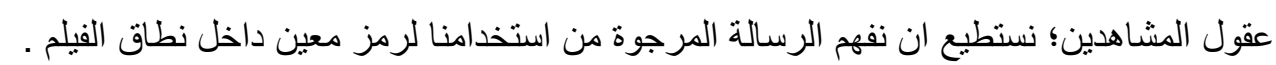
و الإنسان مزود بقوي كبيرة لتنقل إليه العالم الخارجي؛ وأول هذه القوى الحسية هو الحواس أو الأجهزة الحسية التي تمثل

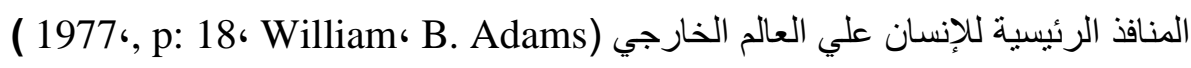
وقد حصر العلماء الحواس البشرية في إحدى عشر حاسة متميزة تجنمع في أجزةة خمسة وهي: البصرية، والسمعية، الحس جسمية، و الكيمائية، والحس حركية؛ ودرجة التميز في كل إحساس من هذه الاحساسات تختلف عن الآخر الذي يليه. وبذللك يكون أدقها الحاسة البصرية وعنصر ها المستقبل هو العين، التي تتأثر بالموجات الضوئية المنعكسة من الأجسام

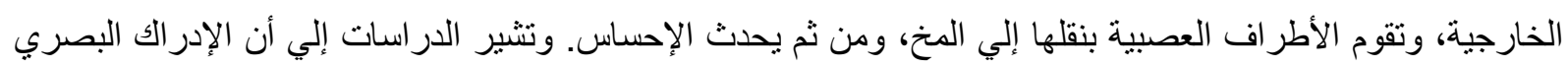

يحتل الموقع الأول في القوي الإدر اكية للإنسان حيث تزوده الرؤية بادر الك شامل للمحيط المرئي بطريقة مباشرة.

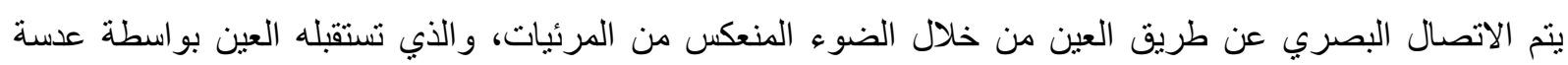
الثبكية فتتكون لديه صورة نمطية لدرجات مشعة المدخل المتفاوتة من الأسطح المتعددة، والأثياء الموضو عية أو المكونة

( p:203،1991،Hoffman ، D. ) التلك الأسطح

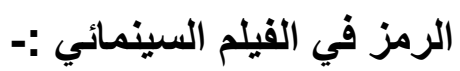
معنى الرمز في مجال الفيلم السينمائي شيء يحل محل شيء الهي إذ فهو يقوم بتوصيل شيء اخر عن طريق ابراز او اثارة

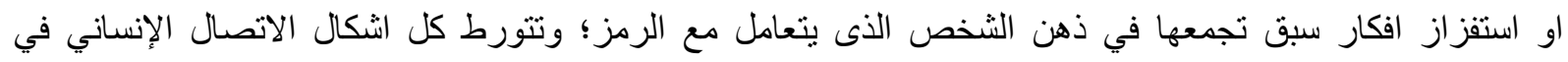

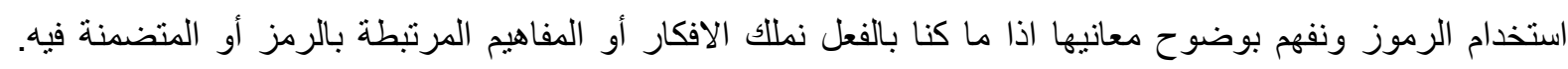

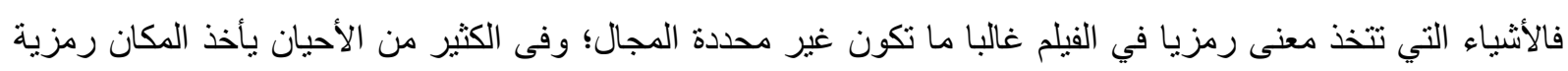

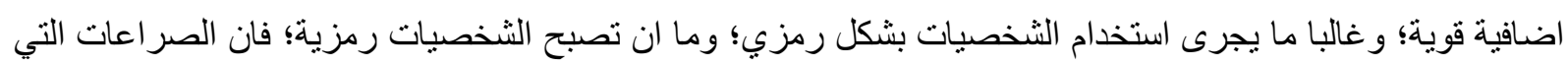
تحدث في داخلها تصبح رمزية ايضا؛ ولذلك فمن الجوهري ان تكون على ادرالك بوعى لطبيعة التوصيل الرمزي في

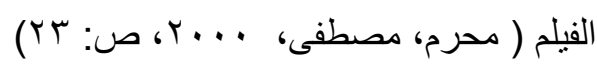

\section{تأثثير السينما في القنون :-}

اسهم اختراع التصوير السينمائي في اثراء الثقافة الانسانية بشكل عام؛ حيث عملت السينما على استنساخ الواقع بشكل مختلف يخرج من خلال عمل فنى و هذا العمل الفني يعتمد في وجوده على التفرد؛ فيخرج العمل الفني من محيطه الخاص

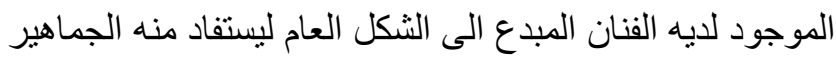
ولذلك ظهرت طبيعة عالمية للرمز لا يختلف عليها المشاهدين في مختلف انحاء العالم لأنها تعتمد على النواحي التقافي و السياسي و الاجتماعية التي قد تكون موجودة في عدة اماكن بنفس المعنى مع اختلاف الاساليب . 
أدت الفنون البصرية الى ظهور العديد والعديد من التطورات التكنولوجية في مجال التصوير الفوتو غرافي والسينما . أدت التطور ات المتلاحقة في أنتاج الأعمال الفنية الى تطور ات مهمة تالية في حباة الأنسان؛ وفى اثكال الثقافة الانسانية

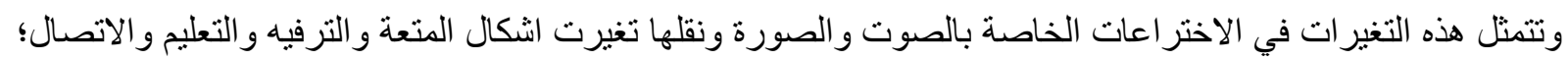
ومن هنا احتلت السينما بتطور ها وتقدمها التقني شكل سينمائي مميز ومختلف مما جعل للسينما شكل تقنى مختلف ولغة خاصة ولعل كل هذه التطور ات اظهرت تطورات كبيرة في عملية احساس المتفرج والقدرة في التأثير على المشاهد مثلما يحدث اليوم.

مما ادى الى وجود تفاعل قوى بين صانعي الافلام والمشاهدين ولذلك ظهرت قيمة و أهمية الرمز بشكل كبير داخل الفيلم

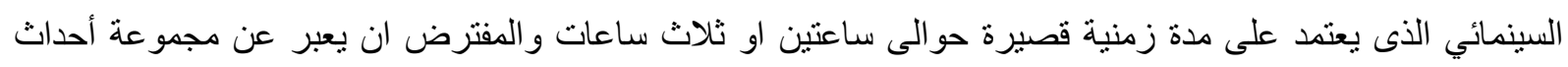

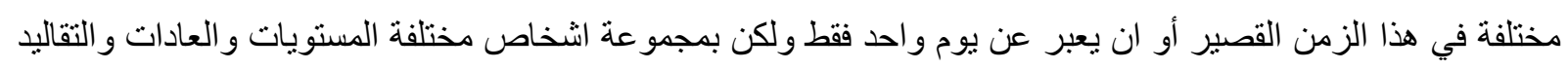

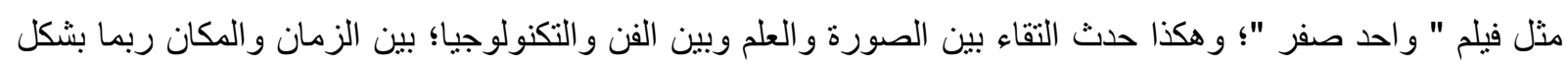
غير مسبوق في التاريخ.

طبيعة الرمز العالمية: - تعتبر الرموز العالمية رموزا جاهزة بحيث تكون بالفعل محتوية على قيم ارتباطات يفهمها

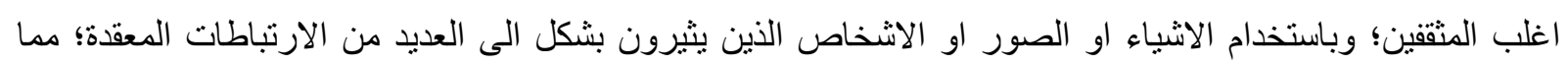
يتيح لصانع الافلام خلق المواقف المرتبطة والمشاعر داخل محتوى افلامهم فهم يحتاجون الى استخدام الرموز بشكل مناسب ليستفيدو ا كاملا من قوتها الاتصالية. وقد تتنوع ردود الافعال من جر اء استخدام الرموز تبعا لطبيعة الرمز واهميته بالنسبة للجمهور المشاهد من مو اقف و افكار

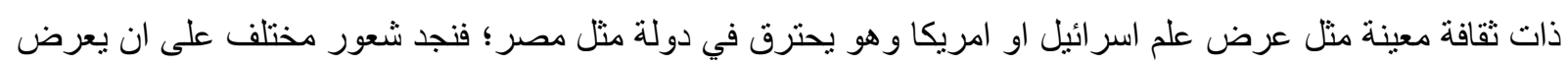
هذا المشهد في امريكا وهكذا. و الكثير من الرموز العالمية مشحونة بمعانيها من الخارج خلال ارتباطات ماضية بأناس او احداث او اماكن او افكار اكثر من خلا سماتها الداخلية ؛ فمثلا ليس هناك شيء يكمن في شكل الصليب؛ بحيث يوحى بالمسيحية فيما عدا القيم والافكار

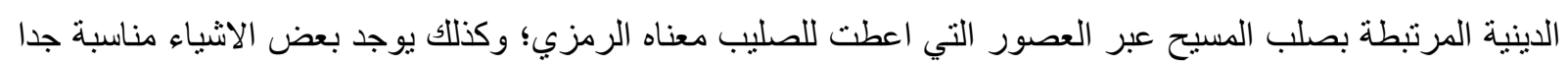
كرموز مثل استخدام الصقر مثلا كرمز للموت دون الحاجة لتقديم قيمته الرمزية؛ وهذا يرجع بالطبع الى مظهره؛

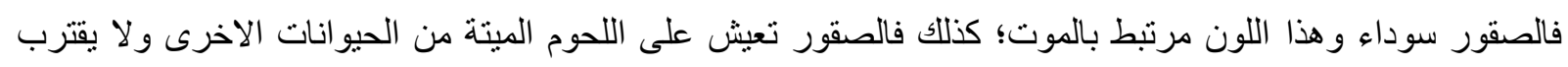

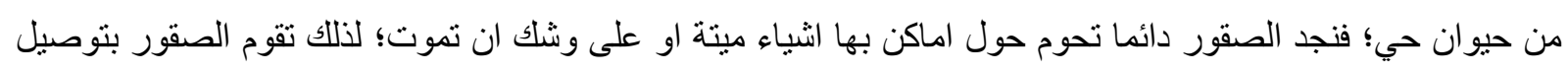

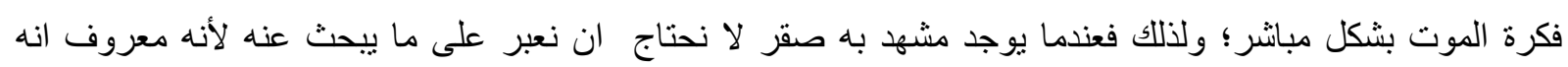
ييحث عن الحيو انات الميتة فتتساوى عادات او اساليب الحياة عند جميع الصقور في الدلالة في تقرير معانيها الرمزية.

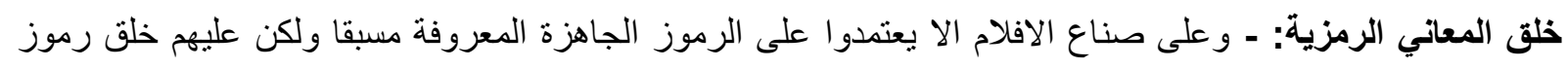
عن طريق شحنها بالمعنى من مضمون الفيلم نفسه. يجب اولا تحميل شيء ملموس او صورة بشحنة كهربائية من الارتباطات و المشاعر و العو اطف والمو اقف؛ ومن ثم

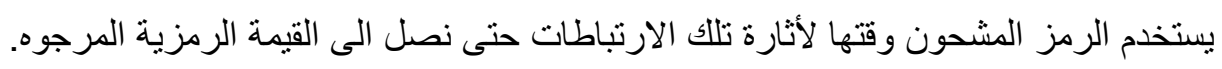

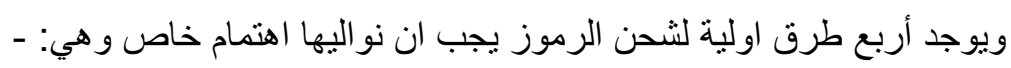
1- خلال التكرار: - ويتم ذلك عن طريق لفت النظر الى الثيء بشكل أكثر مما بيتحقه مجرد شيء بسيط سطحي؛ ومن خلال هذا التكر ار يصبح للثيء دلالة وقوة رمزية عند كل ظهور. 
2- خلال قيمة تضيفها احدى الثخصيات على شيء: - ويتم شحن شيء ما رمزيا عندما تضفى شخصية معينة قيمة او

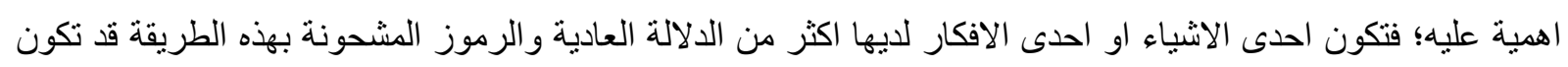
نسبيا ذات اهمية اقل ووظيفتها فقط ان تقدم لنا بعدا رمزيا في الثخصية او يكون لديها دلالة اكبر بالنسبة للبناء الدرامي.

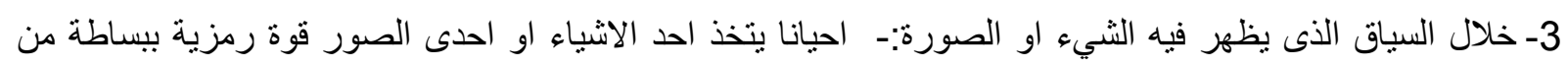

خلال وضعه في الفيلم وتنبني شحنته الرمزية خلال الارتباطات التي تم خلقها عن طريق :أ- عن طريق علاقتها بالأشياء الاخرى في نفس النكان. ب- عن طريق علاقة قام بها المونتاج. ج- عندما تحتل مكانا هاما في بناء الفيلم .

4- من خلال التوكيد الخاص المرئي والمسموع او الموسيقى :- للفيلم طرقه الفريدة لثحن وتحقيق الرموز وتوفير

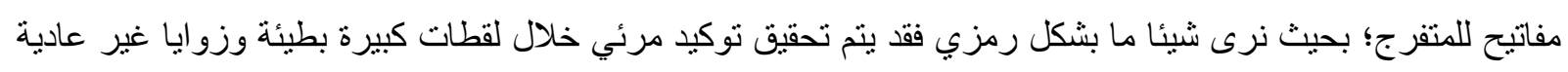

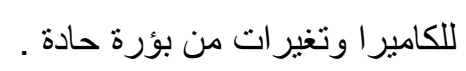

\section{الأنماط الرمزية والمتواليات :- الردية}

قد تؤدى الرموز وظيفتها بشكل منفرد دون علاقة واضحة بالئه بالرموز الاخرى؛ فهي غالبا ما تتفاعل مع رموز اخرى بما قد

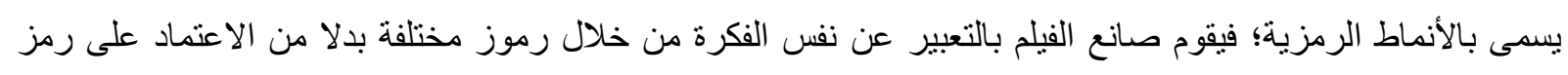

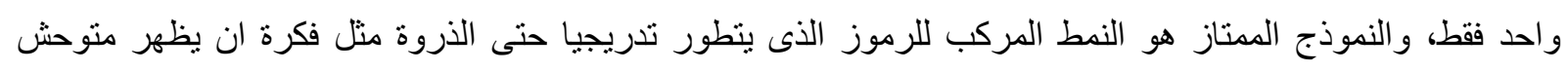

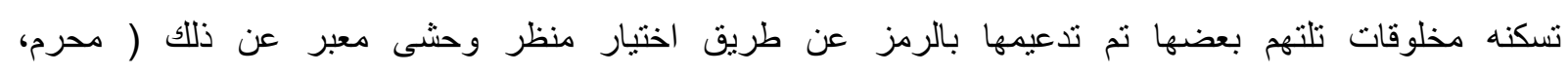
مصطفى، (.... (

\section{أنواع الرموز المستخدمة في الفيلم السينمائي والتي تؤثر على الادراك :- رموز

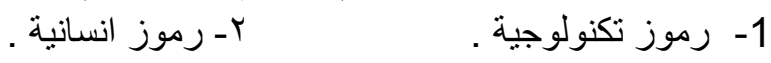

أولا الرموز التكنولوجية :- هي الرموز التي تعلن عنها الصورة نفسها؛ فالصورة تمر بعدة مراحل تكنولوجية؛ هذه

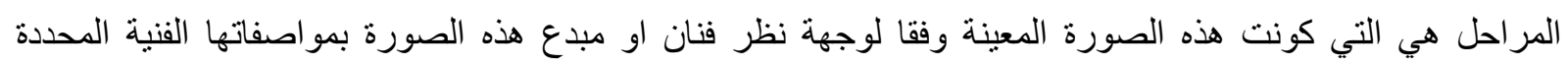

لتعطى انطباعا معينا.

فالضوء والزاوية ودرجة حساسية العدسة و عملية التصوير وعملية التحميض؛ جميع هذه المر احل هي التي أعطت وكونت هذه الصورة وفقا لمفهوم ووجهة نظر الفنان لتعطى المتلقي انطباعا معينا . ويمكن ان نعبر عن مفهوم الرموز التكنولوجية بأنها الخطوط أو الاشار ات المناسبة من وجهة نظر الفنان الفنان و التي تحتل مادة

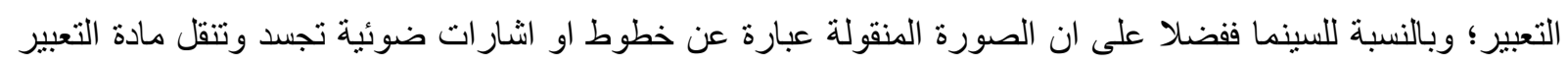

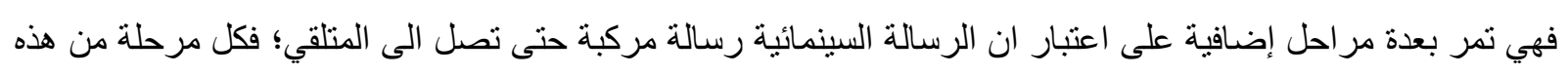

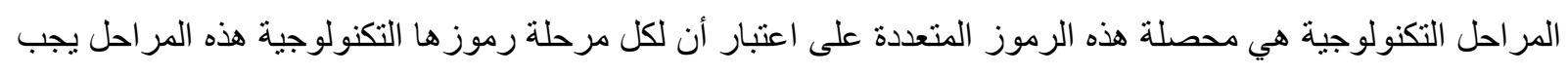
أن تكون متكاملة ومتداخلة حتى تعطى المتلقي الانطباع المطلوب. 
فالصورة المتحركة هي صورة مركبة او رسالة مركبة ؛ فكل مرحلة من المر احل التكنولوجية السابقة تحتوى على رموز

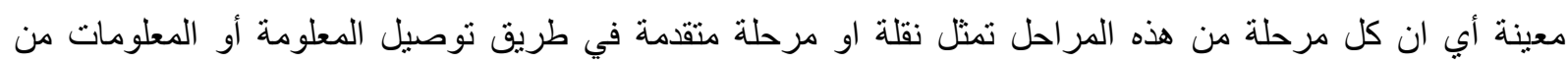

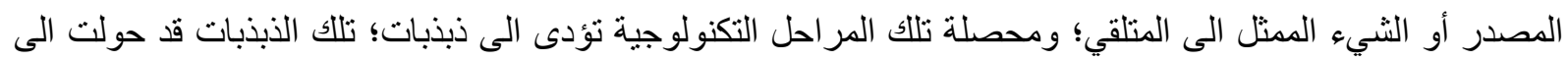

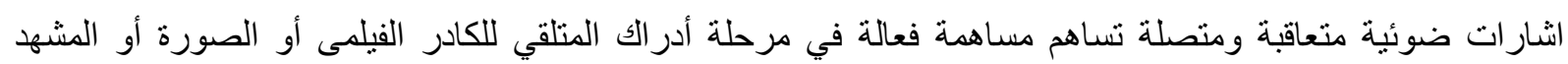

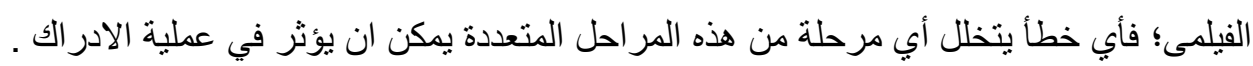

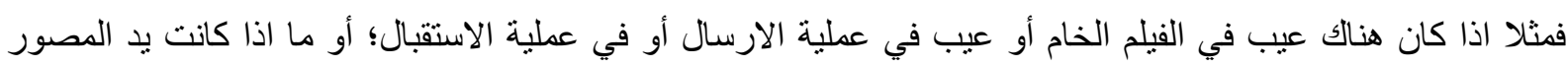

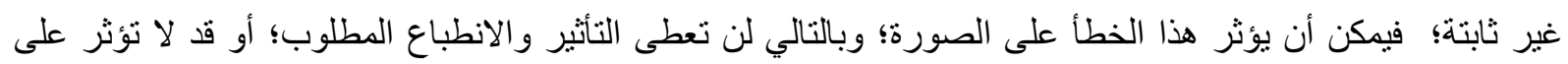
الأدر اك . ومن ذلك فان الرموز التكنولوجية او الرموز الفنبة المرتبطة بتكنيك الصورة تنقسم الى مر احل متعددة؛ كل مرحلة تضيف

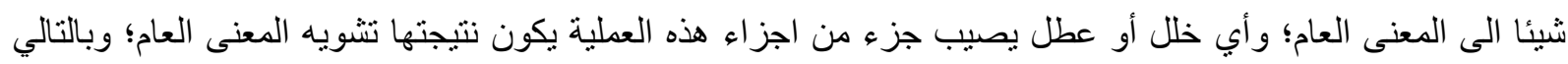

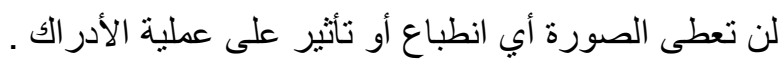
ثانيا الرموز الإنسانية :- اذا كانت الصورة السينمائية تحنوى على رموز تكنولوجية متعددة يمكن عن طريق مبدعها التعرف على مواصفاتها ومفهومها؛ فالصورة السينمائية تحتوى ايضا على رموز إنسانية . فنحن نعلم أن المتلقي أو المستقبل للصورة السينمائية؛ تقل قدرته على تفهم الصورة أو الرسالة المركبة كلما كانت تجاربهابه

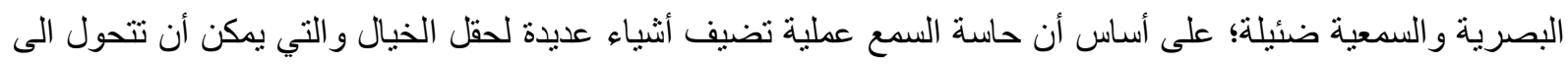

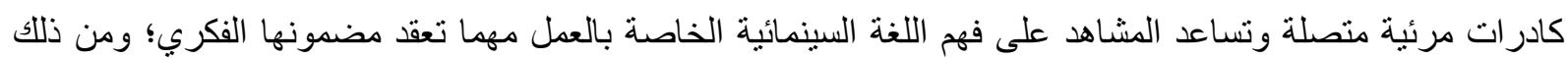
يوجد علاقة قوية بين الرموز الإنسانية ومدى كثافتها وبين القدرة على حل الرموز التكنولوجية وفلك غموضها.

\section{ويوجد عدة نتائج لاستخدام هذه الرموز وهى: -}

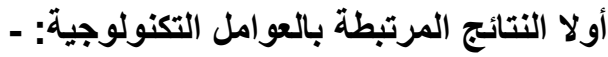
ا-ان اعادة تثكيل الواقع من خلال الصورة السينئملئية تمنحنا إحساسا بالحقيقة وهذا الاحساس ناتج من هذا التشابه بين الواقع المادي أو اللالغوى والواقع المشكل أو المعكوس في هذه الصورة أو المشهد السينمائي؛ فهذا المشهد هو أعادة

تشكيل الو اقع. r- ان الواقع الممثل يتدخل في تثكيله عدة خطوات تكنولوجية؛ فالرسالة السينمائية ما هي الا وسيط بين الألة وهى

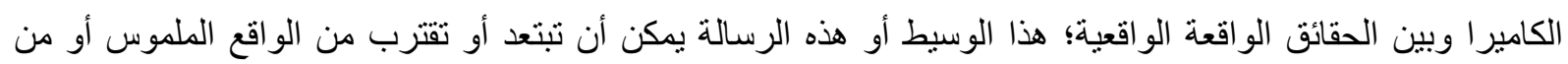

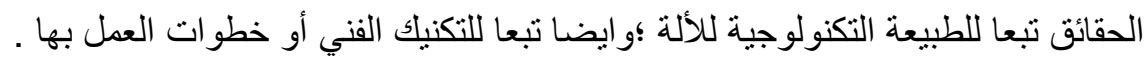




\section{ثانيا التتائج المرتبطة بالعوامل الإنسانية: - وهي لها علاقة بالمشاهد أو المتلقي}

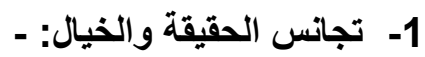

مشاركة المشاهد مع المبدع من خلال الالة تعنى التزاما منه للاشتر الك في عملية التنقل من مكان لأخر مع تحركات

الكامير ا؛ فتغير المشاهد وفقا لتحركات الكامير I 1 تعطى إحساسا بالتنقل بين الأماكن المختلفة.

2- عوامل تكنولوجية تتذاخل في عدم الاحساس بالحقيقة: -

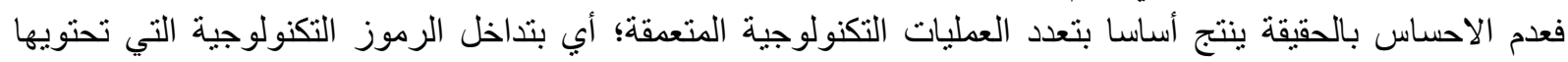
السينما؛ فاذا لم يوفق المونتير في عملية المونتاج نتيجة لذلك يفقد المشاهد قدرته على أدراك المعاني وذلك لكثافة الرموز

التكنولوجية.

\section{3- العلاقة المتثابكة بين السياق الفيلمى وينية المجتمع: -}

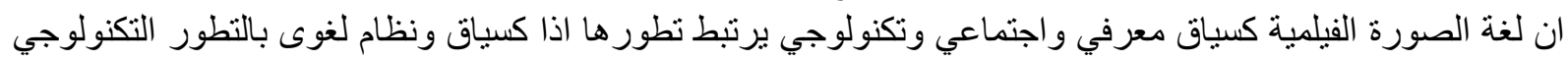
و العلمي والصناعي؛ على اعتبار أن المجتمع و التكنولوجيا يدخلان طرفا من أطر اف هذا النظام اللغوي. وبمعنى أخر يساهم هذا التطور التكنولوجي والاجتماعي والعلمي مساهمة فعالة في بلورة وتكامل الاطار الدالاي و المعرفي لهذا النظام؛ فمن خلال التطور يضاف العديد من المفردات اللغوية ويضاعف حصيلتها من الرموز التكنولوجيا و الانسانية التي توظف في عملية التعبير عن المعاني الانسانية المجردة. ومن ذلك فالرموز التكنولوجية ترتبط ارتباطا وثيقا بالتطور العلمي و التكنولوجي في المجتمع وبذللك تظهر فاعلية الصورة الفيلمية على التعبير عن الفكر والثقافة . أما الرموز الانسانية فترتبط ارتباطا وثيقا بالتطور الفكري و الثقافي والاجتماعي والاقتصادي و المعرفي بصفة عامة؛

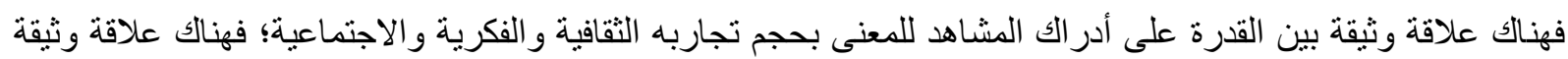
بين القدرة على ادر اك المشاهد للمعنى وربطه للمعاني و الافكار التي يعرضها في خلال سياق موضو عه كرمز سينمائي (

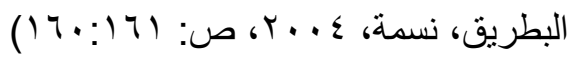
وبعد ان تحدثنا عن انواع الرموز من كونها انسانية وتكنولوجية وجدت طريقة تصنيف أخرى من كونها رموز مركبة و غامضة أو تشبيهات .

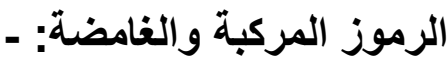

بالرغم من ان صناع الافلام بريدون التعبير عن افكار هم بشكل و اضح فقد لا يريدون دائما ان يعبروا عنها بشكل بسيط او بوضوح تام؛ ولذلك فقد تبدو بعض الرموز بسيطة جدا وواضحة وقد تكون أخرى معقدة وغامضة فلا يمكن تفسير هذه الرموز بمعنى واحد معين وواضح فقد لا تكون هناك اجابة صحيحة وواحدة لما يعنيه الرمز المقدم لنا ولكن تفسيرات

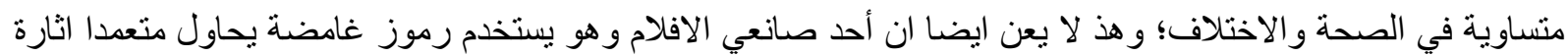
حيرتنا؛ فعادة ما يكون الغرض هو اثر اء العمل او الارتفاع به من خلال التعقيدات.

اقرب ما ينتمى اللى الرمزية في الفيلم هو استخدام صانع الفيلم لما قد يسمى بالتشبيهات المرئية فبينما يقوم الرمز مقام شيء ما اخر او يمثله يعتبر التشبيه السينمائي مقارنة موجزة تساعدنا على فهم و أدر الك احدى الصور بشكل افضل بسبب تشابهها بصورة اخرى؛ ويتحقق هذا عادة من خلال المونتاج المتعارض لصورتين في لقطتين متتاليتين فلو كان صانع الفيلم مثلا يريدنا أن نفعل بطريقة معينة لمجموعة من السيدات المسنات في وسط جلسة نميمة فقد يقطع من لقطة لهن مع 
بعضهن و هن يثرثرن الى لقطة كبيرة لرؤوس عدد من الفرخات تقرقر في اهتياج؛ وبذلك فعن طريق اصطلاحات بصرية يخبرنا صانع الفيلم بان السيدات المسنات المؤثرات هن الفرخات العجائز؛ وفى هذه الصورة الثنانوية للفرخات تعتبر هنير غريبة بمعنى انها ليس لها معنى في سياق المشهد نفسه ولكن صانع الفيلم أقحمها بشكل مصطنع في المشهـ. وفى الفيلم الو اقعي او الطبيعي قد تبدو مثل هذه التشبيهات الغريبة محشورة وثقبلة أو أيضا سخيفة وتدمر معنى الو اقعية التي قد تكون هامة جدا بالنسبة الى الفيلم؛ ومن ناحية أخرى تسنطيع الأفلام الكوميدية أو الفانتازيا استخدام مثل هذه

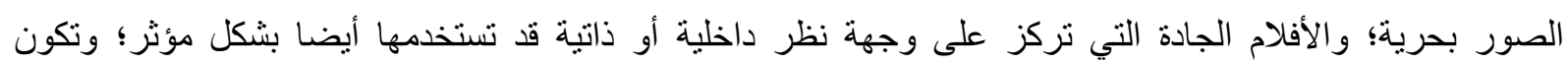

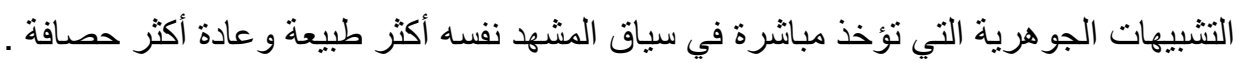

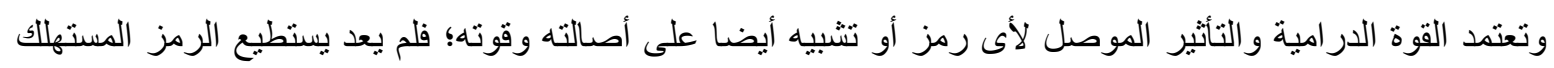
البالي أن يحمل معانى ثقيلة والتشبيه الذى أصبح مكررا يصبح معوقا أكثر منه مساعدا؛ وتسبب هذه الحقيقة مشاكل عديدة في مشاهدة الأفلام القديمة لأن كثير ا من التشبيهات و الرموز المستخدمة تبدو مكررة اليوم؛ رغم أنها قد تكون بالفعل جديدة

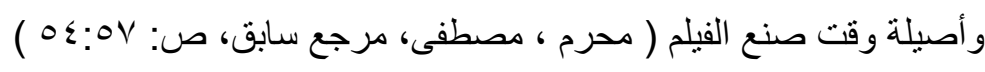

ثانيا : فيلم الاراجوز

تاريخ عرض الفيلم: 1919 ، فكرة واخراج: هاني لاشين، سيناريو وحوار: عصام الثماع، تصوير : محسن أحمد. تمثيل: عمر الثريف؛ مرفت أمين؛ هشام سليم؛ عبد العظيم عبد الحق؛ أحمد خليل؛ سلوى خطاب، مدير الإنتاج : محمد

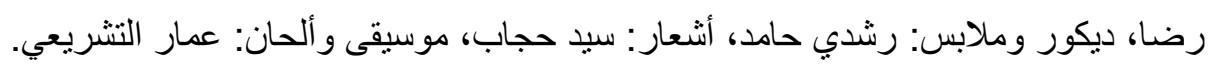

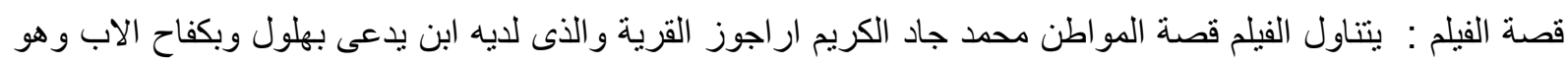
يعمل اراجوز استطاع ان يعلم ابنه ويخرجه من الجامعة الا انه تمرد على مهنة ابيه وعمل الابن عند احد اهم رجال الاعمال من ابناء القرية ولكن يبدا صر اع المال حيث نجد رجل الاعمال يريد ان يقيم مشروع سياحي كبير في الارض لهرد

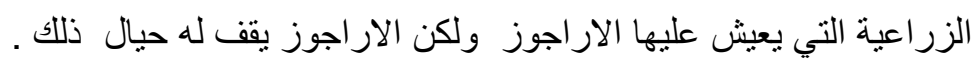

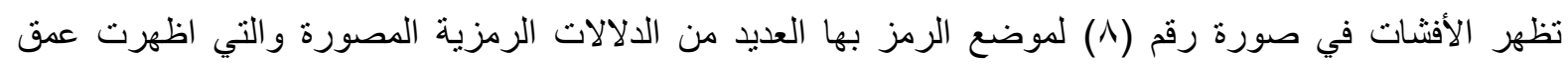
صناعه في محاولتهم لإبراز و التعبير عن فكرنهم دون اى تهاون او استسهال، بالإضافة الى ان كتابة الاسماء في التتر

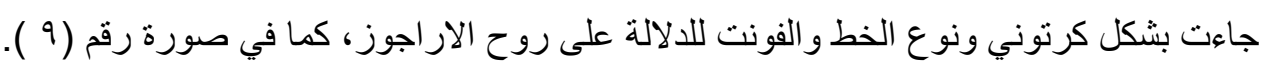
واول الاسقاطات الرمزية على صورة الافيش: والمتمثل في منظر البطل والبطلة (عمر الثريف؛ مرفت أمين)؛ وما يحملوا من أثقال عبارة عن عدة الار اجوز والتي بستخدمها في مهنته هذه المهنة الثعبية الموجودة في العديد من القرى المصرية وهذه الاحمال هي في الواقع رموز؛ لإسقاطات أخرى مرتبطة بمدى المعاناة التي يعانيها ابناء هذه هذه الطبقة الكادحة في المجتمع من عمال وحرفين لكسب الرزق ومحاربة الفساد كما سنعلم من خلال تحليل الفيلم ، كذلك أظهرت

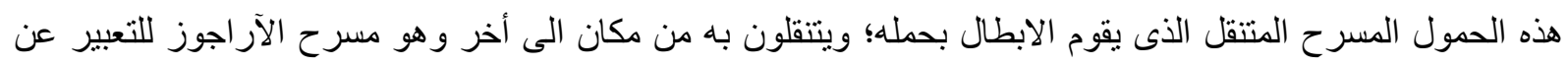
رسالتهم في كل زمان ومكان والتي يستميت اصحابها في ارسالها والتعبير عنها مهما كلفهم ذلك من معاناة على مدار 


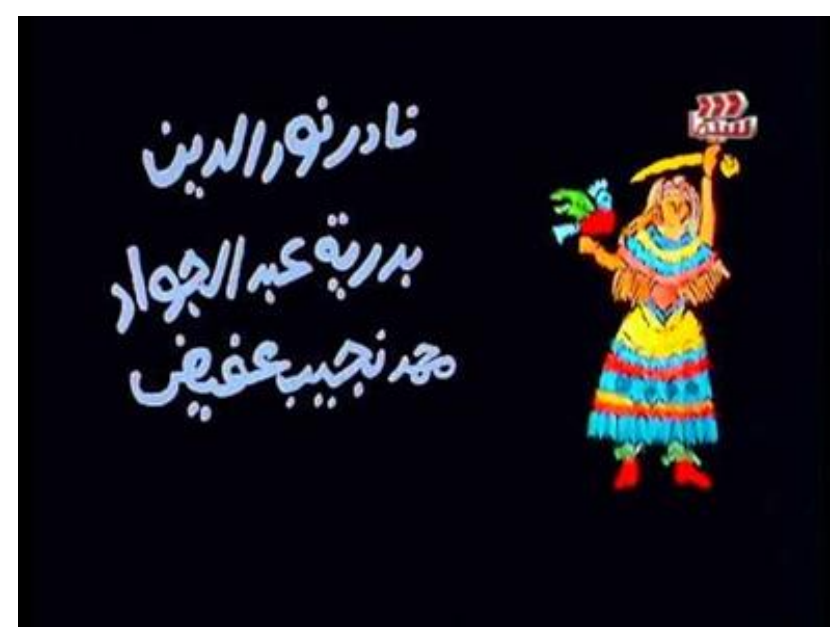

صورة رقم (9) لتتر الفيلم حيث استخدام الشخصيات الكرتونية

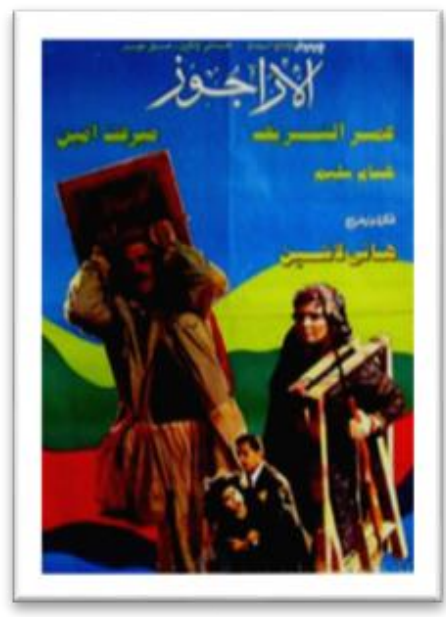

صورة رقم (^) يعرض افيش الفيلم وأبطاله

كذللك الإسقاط الرمزي الثاني: من خلال الفيلم والذى يظهر ابن البطل (هشام سليم) والذى يظهر شبه ساقط وبحجم صغير حدا بالنسبة لباقي الكدر على التتر للالالة على سقوطه الى هاوية الفساد بعد أعاقته لوالده، وتمرده عليه ومناصرته

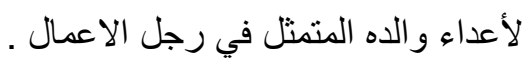
اما الاسقاط الرمزي الثالث: فيظهر منتثل في الوان التتر الكثيرة والمتنوعة ما بين الاحمر والاصفر والازرق والاخضر؛ و هى ايضا نوع من الدلالة والرمز على حياة البطل المختلفة ما بين السعادة و الثقاء؛ بالإضافة الى انها تعبير عن مهنته التمثيلة في عرض مسرح الآر اجوز الذى يتسم بالألوان المبهرة لجذب الأطفال و الثباب على عنى حد سو اء.

تحليل الرمز في فيلم الآراجوز من الناحية الموضوعية: نجد ان المخرج: هاني لاشين؛ المؤلف: عصام الثماع؛ جعلوا أحداث الفيلم تدور في ثلاثة محاور أساسية وهي (الرمز؛ الو اقع؛ الخيال) يعتبر فيلم الآراجوز من أكثر الأفلام وضوحا في التعبير عن الرمز حيث؛ نجد أن صناع هذا الفيلم قد استخدموا الآراجوز أو الدمية الخشبية التي هي البطل في هذا الفيلم في التعبير عن هذا الثعب الفقير البسيط في مكافحة للظلم و الفساد؛ حيث أن عرض الآراجوز الذى وجد من خلال أحداث الفيلم لم يكن للإضحاك فقط ولكن هو في الحقيقة نوع من انواع التعبير

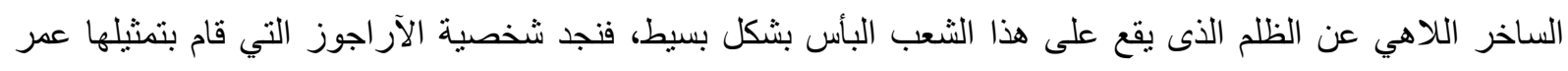
الثريف تعبر كأر اجوز مرة؛ وكإنسان مرة أخرى يعبر عما يقع عليه من ضغوط سواء تقع عليه أو على من حوله.

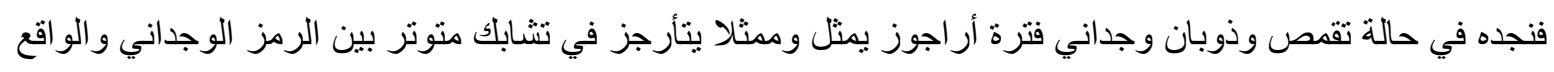

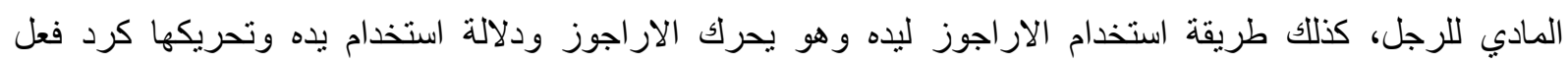
لاستخدام الاراجوز في اليد فيده اخذت على نفس هذه الحركات بشكل مستر وفى كل موقف اثثاء حديثه، وشكل يد

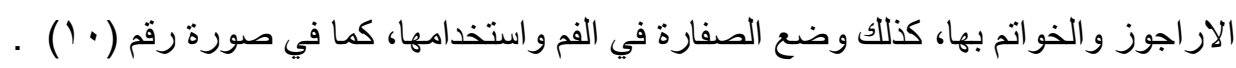




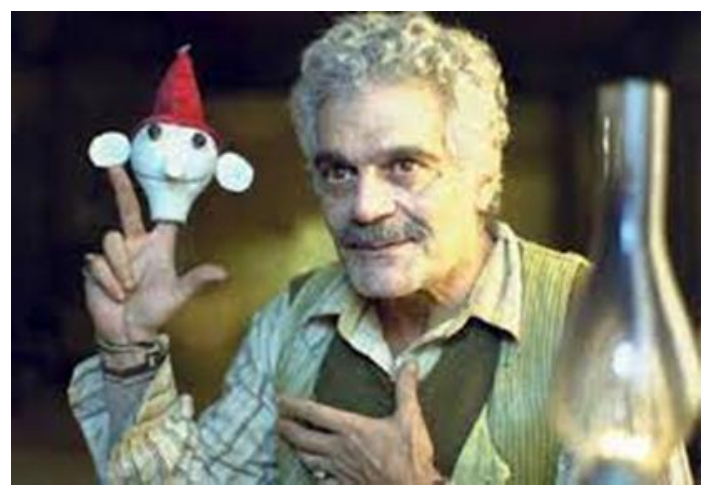

صورة رقم (• 1) لطريقة استخدام الاراجوز ليده

و هذا الو اقع المادي للرجل يكمن في ذلك الأب (عر الثريف) الذى يشعر بجحود أبنه الذى كبره و علمه؛ ولكنه يرفض أن يساعده في مهنته ويتحول الى شخصية غير سوية انتهازية؛ كما يظهر في الصورة رقم (1') .

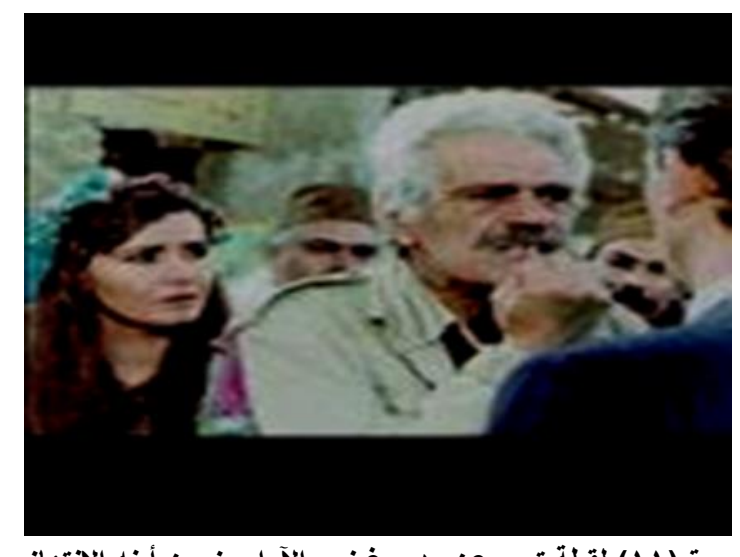

صورة (1 1 ) لقطة تعبر عن مدى غضب الآراجوز من أبنه الاتتهازي

أما و الده فدائما ما يتكلم بالحق و العدل ويقوم بخدمة نفسه ويتنقل هو وأرجوزه ومسرحه الصغير وأدواته من مكان الى

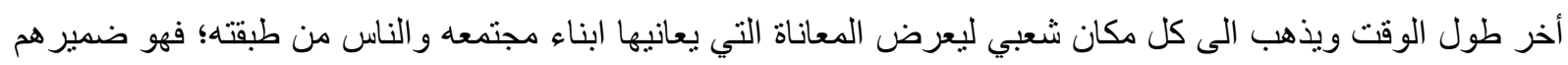
الحى الذى يظهر معانتهم ؛ فهو يملك أدو ات المسح من جمهور و القاء وحركة ولكن ببساطة وتلقائية ويعرض موضو عاته بشكل رمزي تلقائي وعفوي وواقعية هذا الأراجوز في أنه لا يحتاج الى المسرح بمعناه المفهوم من خشبة مسرح ومدرجات ومقاعد وبوابات مختلفة وستائر واضاءة وديكور وكهرباء وممثلين بل يقوم بكل ذلك في الهواء الطلق بين الأشجار و النخيل و الأسواق بمبالغ رمزية يقوم الرمز بإثباع متطلباتهم النفسية، فيقوم بالتعبير عن موضو عاتهاه برؤى تثنبه الملاحم الثعبية البسيطة حاوى داخلها الموروث الثعبي في نواصل وتوارث مستمر عبر الأجيال لقيم العرف والتقاليد

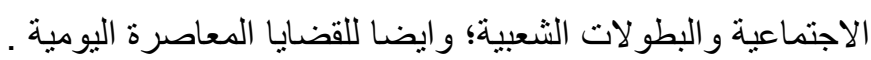
ونجد البطل عمر الثريف ينفصل عن دميه أحيانا ويناجيها أحيانا ونراه يرفض انيه يكوة يكون أراجوز خشبي ويسعى للزواج مرة اخرى بعد ان كبر أبنه وذهب الى الجامعة؛ كما أننا نجده في بعض المواقف يرقص ويغنى كأراجوز أدمى حتى ونى يظهر روح الثباب و المرح بداخله ويسنطيع أن يتزوج من الفتاة الثابة ميرفت أمين في الفيلم. ونجد أن من ساعد في تكثيف الإحساس الدرامي هو الموسيقى التصوير؛ ونجد أيضا رمز الفساد و الظلم و اضح في العددة ورجاله الذين يقومون دوما؛ بطرد الآراجوز الفقير البسيط الذى يعرض أثياء لا تجذبهم لأنها تعبر عن الفساد الموجود

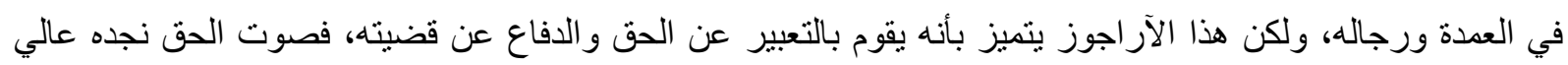

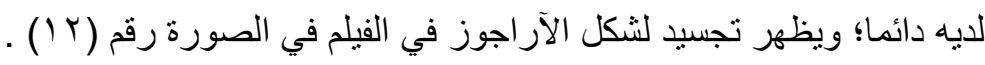




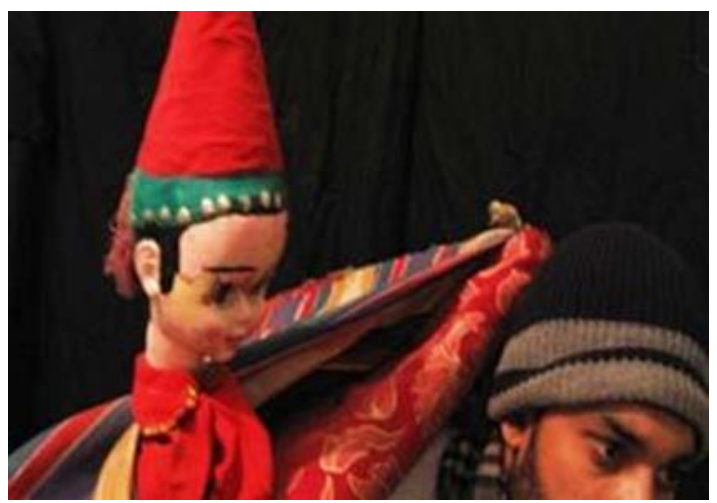

صورة رقم (r ا ) الآراجوز الامية أثناء قيامه بالتعبير عن معاناة المواطنين

ومن بين الإسقاطات الرمزية ومن هذه الإسقاطات الرمزية الحوار الذى دار بين عمر الثريف ودميته بعد نكسة VT فقال

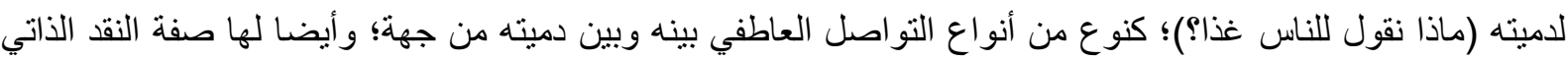
المباثر من جهة أخرى؛ فلديه مسئولية إعلامية تجاه قريته التي سيقابل أهلها ويجب أن يكون جدير بهذه المقابلة، و عندما دخل القرية التلفزيون والفيديو والالعاب الالكترونية والسوبر ماركت هتف الأطفال في وجه الآراجوز مطالبينه بأفلام مماثلة لما يروه في هذه الحياة الجديدة؛ بعد الانفتاح الاقتصادي كأفلام المرأة الخارقة؛ كرمز ونتيجة لمسح الهوية التراثية و الموروث الثعبي من وجدان الصغار والكبار غير المتعلمين نتيجة للانفتاح غير المتقن على كل جديد أتى من الخارج في تناول سلبى للانفتاح، ومظاهر هذا الانفتاح ظهرت كرمز في ابن عمر الثريف هشام سليم وهو الجامعي نتاج هذا العصر الجديد الذى يتميز بالانتهازية و المصالح فوق كل شيء بزواجه من فتاة من أسرة أحد الراسمالين.

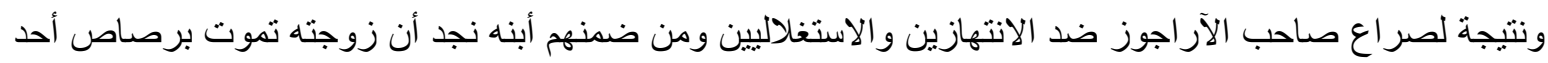
هؤلاء الانتهازيين الذين يحاربهم بعد أن كانت هذه الرصاصة موجهة لأبنه الاستغلالي وتترك له طفلا معبرا عن رمز

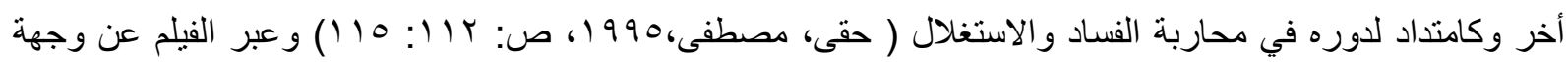
نظر صناعه عن خطر الانفتاح الاقتصادي حسب رؤيتهم وما يريدون ابرازه .

\section{تحليل الرمز من الناحية الفولكلورية:}

تنوعت عناصر الفولكلور داخل الفيلم وذلك نظر التنوع مظاهر الحياة في البيئة الريفية التي صور فيها الفيلم ومنها: اولا : الازياء فنجد زى الاراجوز المتمثل في الجلابية الفلاحي و عليها السديري والجاكت المميز بهم هذا الرجل وحقيبته المصنو عة من القماش و التي يوضع فيها ادو اته البسيطة، كذلك زى زوجنه السيدة الفلاحة حيث الجلابية الفلاحي بالإضافة

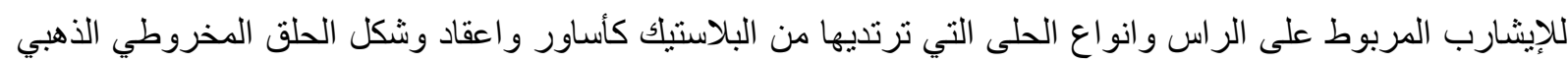
وخلاخيل كما في صورة رقم (r I) ، كذللك ملابس شيخ الغفر المميزة وطريقة وضعه للبندقية وملابس الاطفال في لئي المدارس حيث المر ايل ذات اللون البيج وملابس العدة التي تختلف عن ابناء القرية، ولبس المعلم والتي تظهر مختلفة ، 


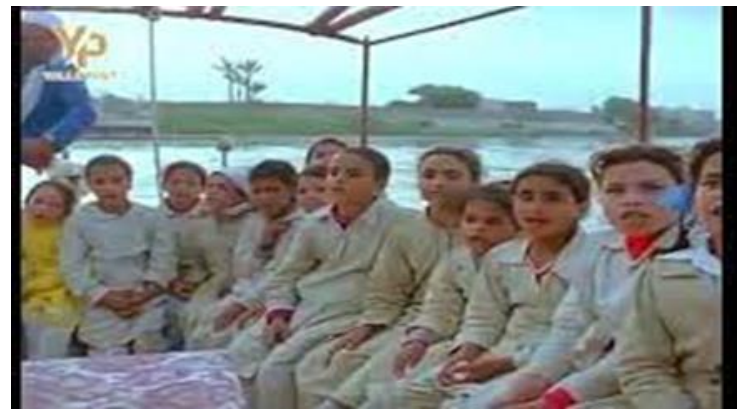

صورة رقم (؛ (1) لأطفال الددارس

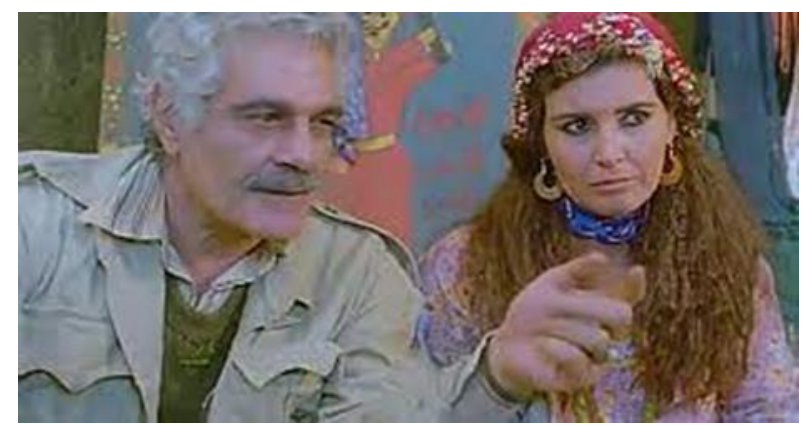

صورة رقم (r I ) للاراجوز وزوجته توضح شكل الزى الخاص بهم

ثانيا: الاثاث فنجد منزل الار اجوز يتسم بالتو اضع حيث استخدام القلة و الزير للثرب، و الطبلية للأكل و الكرسي القصيرة وطشت الغسيل و المنقد و الصنية و الكوبايات والصندوق المعدن و العربة الكارو كوسيلة للمواصلات، لمبة الجاز للإضاءة و الكلوب وباجور الجاز وطنبورة المياه في الحقل كما في صورة رقم (10) و التي تستخدم للزر اعة، بالإضافة الى العديد

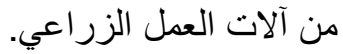

استخدام الخيمة القماش على البحر، ادوات الطعام كالباجور والحلل الالومنيوم ومخرطة الملوخية والفرن البلدي، كما ظهرت عادات الطعام في بعض الاكلات مثل العيش المرحرح و الجبن و الجرجير وهى اكلات فلاحي وتوليد البقرة.

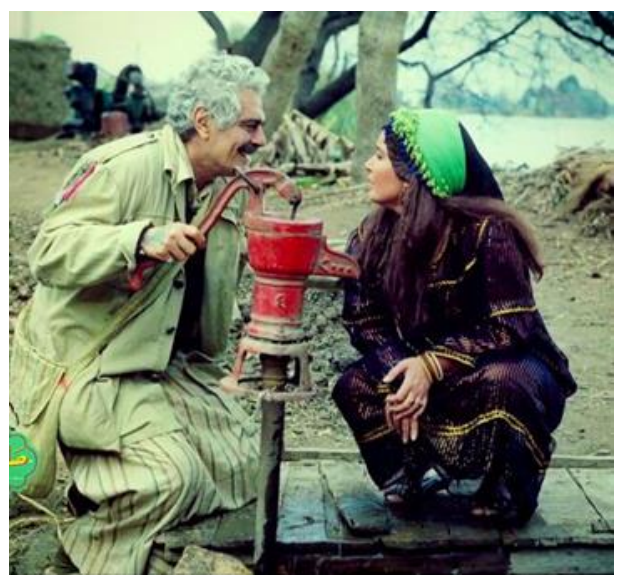

$$
\text { صورة رقم (10 1 ) لطنبورة المياه }
$$

ثالثا: المهن الثعبية وجدنا العديد من المهن مثل البائعين الجائلين مثل بائع الحمص وبائع الايشارب الفلاحي او ما يسمى

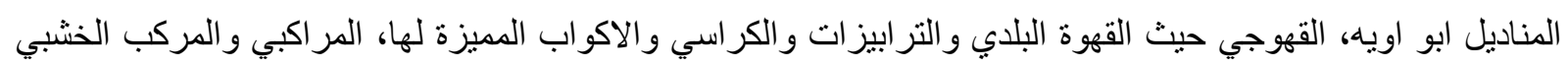
و الشر اعي التي يركبها الاطفال للتنزه.

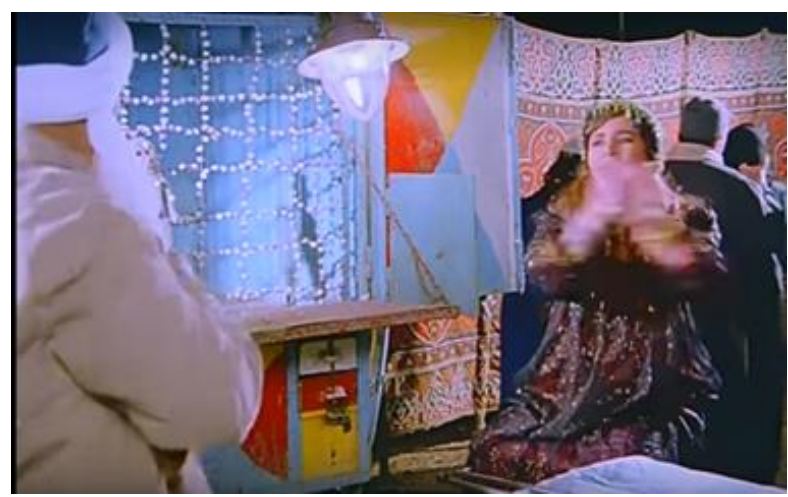

صورة رقم (17 1) للتنشين في احتفالية المولد 
رابعا: الاحتفالات الثعبية وظهرت في المولد وما يوجد به من العاب شعبية معدنية كالمرجيحة الثعبية والتنشين وحلقات الذكر ، كما في الصورة رقم (1 (1).

خامسا: الموسيقى الثعبية وظهرت فيها الاغنية الثعبية والموال الثعبي الذى ظهر اكثر من مرة في الفيلم والأغاني الفولكلورية مثل اغنية العتبة جزاز ورقص الفلاحات عليها كذلك اداء الاراجواز على اغنية ام كلثوم، استخدام الآلات الموسقية الشعبية وعزف الفنانين الثعبية عليها وترديد السيرة الهلالية وذلك عن طريق العزف على البوق والميه المزمار

و الطبال، كما في صورة رقم (lV).

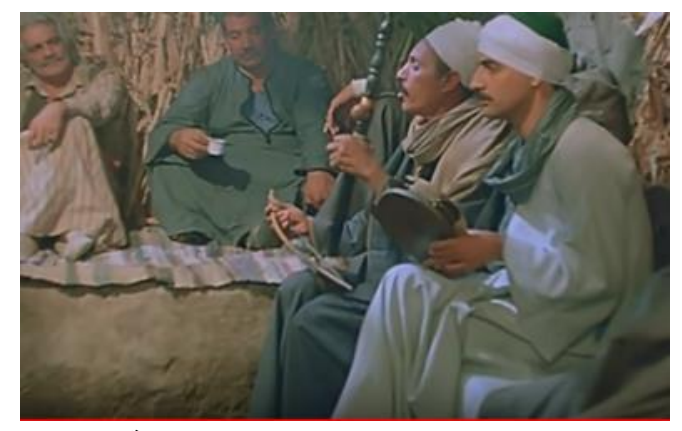

صورة رقم (IV) - لعزف السيرة الهلالية

كما ظهرت المواويل والاغانى والتى يقوم بها الارجوز والتى تحوى الكثير من الموضوعات الفولكلورية وابراز للتطور ات الفكرية و القيم المجتمعية لاى افر اد المجنمع.

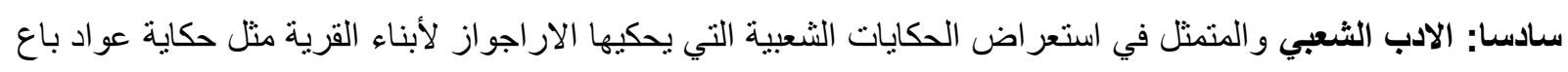
ارضنه و التي يستخدمها الار اجوز.

\section{تحليل الرمز في فيلم الاراجوز من الناحية القنية والجمالية:}

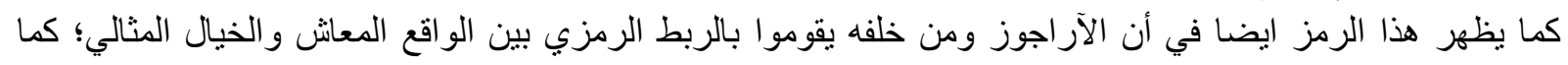

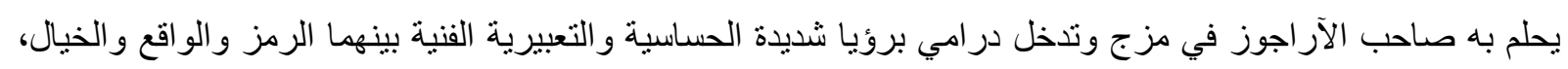

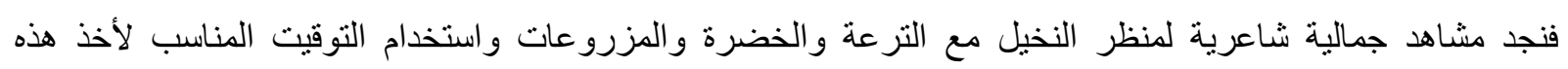
اللقطات في الفجر بعض الاحيان والصباح الباكر احيان اخرى والغروب ايضا كل ذلك لتجسيد رؤية جمالية شديدة الخصوصية وربط الخيال بالواقع، و الذى ساعد على ذلك التصوير و الذى قام به مدير التصوير محسن أحمد حيث أستخدم

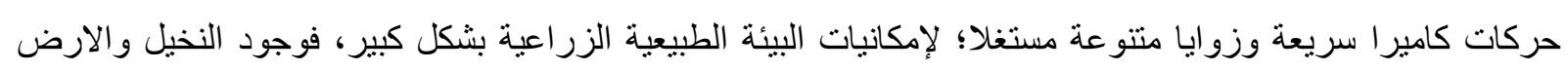

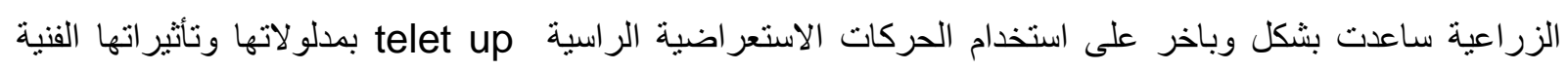

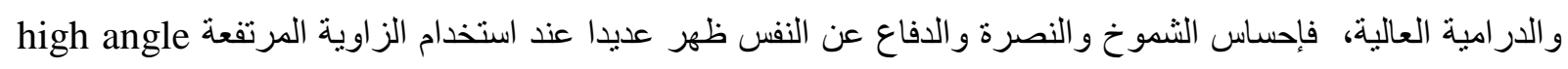

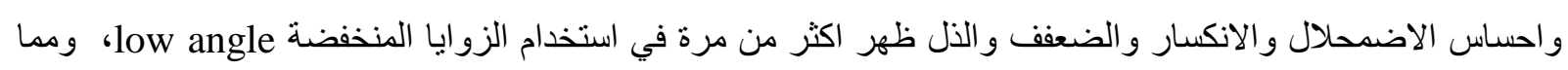

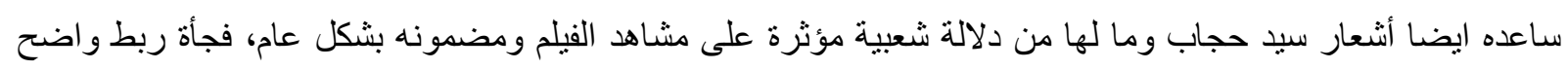

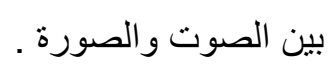

ونجد العديد من الكادر ات المستخدمة في نفس الفيلم بأحجام لقطات مختلفة ومتتو عة ما بين لقطات قريبة Close up shot

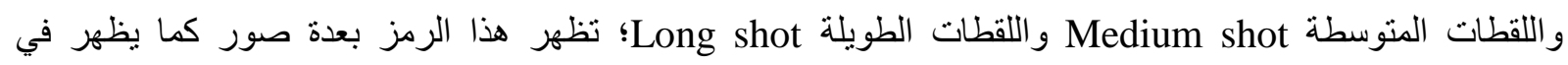

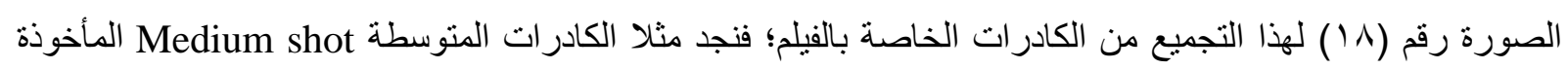
لمرفت أمين تلك الفلاحة البسيطة والجميلة في نفس الوقت وكيف رمز المخرج لهذا الجمال البسيط في أن يجعلها مثلا 
تلبس الملابس ذات الالو ان الزاهية ورغم ذللك تتسم بالرمز للجلباب الفلاحي، بالإضافة لاهتمامها بنفسها رغم كونها فقبرة وبسيطة؛ وذلك يظهر في الكادر المأخوذ لشعر ها وهى تمشطه .

كذللك يظهر من خلال الفيلم العلاقة الجميلة بين صاحب الآراجوز وزجته من خلال الكادرات الطويلة Long shot المأخوذة لهما؛ والتي رمزت بشكل أو بأخر لمدى الحب بينهما رغم زوجهم القريب والذى ييرر في النهاية حزنه عليها

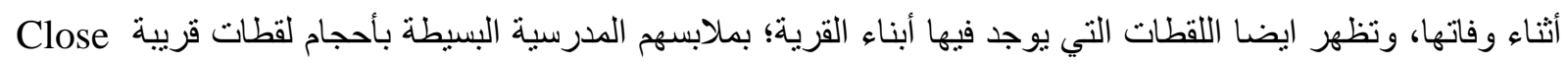
up shot

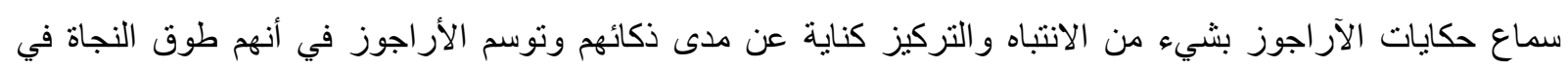
المستقبل . كذلك الرمز الذى ظهر في الكادرات التي ظهر فيها ابن البطل وهو يرتدى البدل الفاخرة مقارنته بأبناء قريته البؤساء

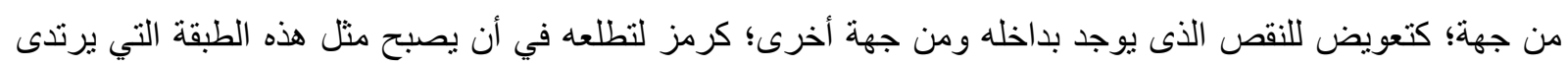

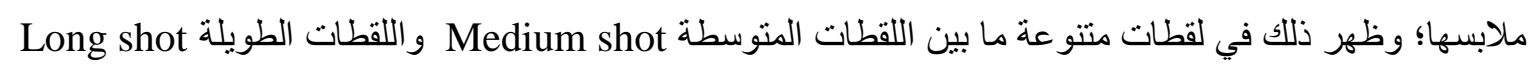

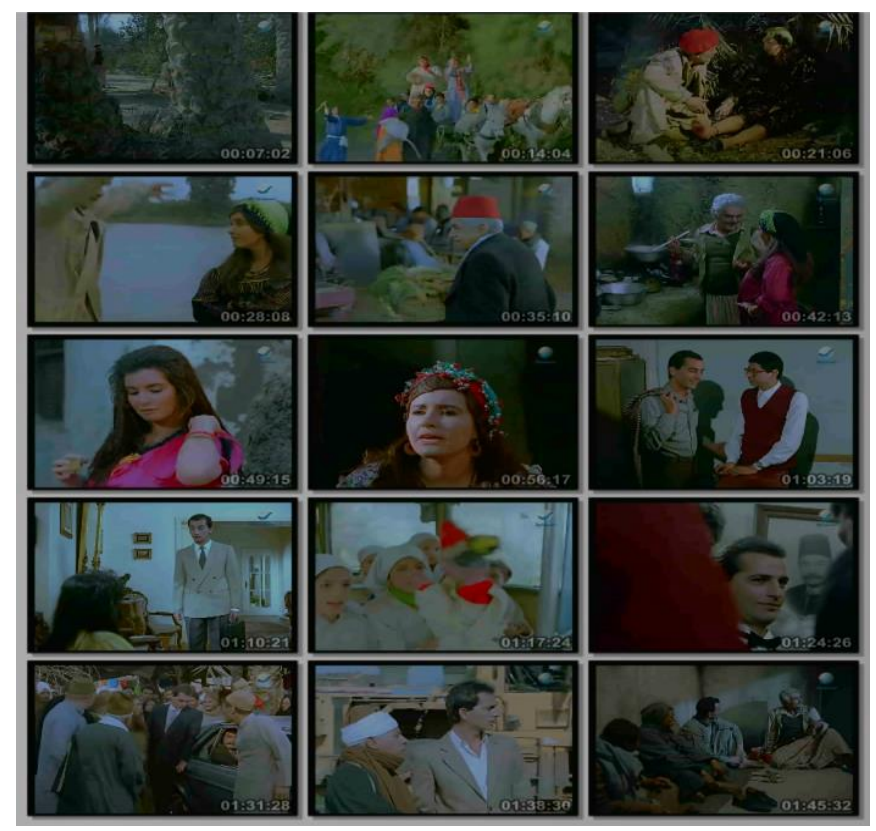

صورة رقم (11 ) يعرض مجموعة من احجام اللقطات المختلفة لفيلم الاراجوز

النتائج:

1- ربط فيلم الار اجوز ما بين الرمزية و الو اقعية و الخيال في حد سواء بشكل به تناغم و انسجام بصرى شديد الدقة

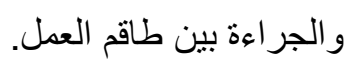

2- توظيف احجام اللقطات بشكل منظم وتيرة فنية سليمة يظهر للك تفصيل تزيد المعنى المرجو داخل الفيلم السينمائي. 3- العناصر الفولكلورية التي تظهر داخل فيلم الار اجوز بها العديد من التفاصيل و التي تحتاج الى دراسات عدة.

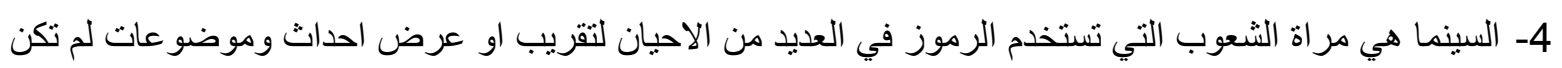
في الحسبان. 5- المجتمع المصري به العديد من القيم و المبادئ لا تتغير عبر اختلاف الزمان و المكان و المنظومة بشكل عام. 
يمكن ان نقول ان الكادر أو الصورة هي الوحدة الأولى في اللقطة الفيلمية أو المكون الأول لبنية اللغة أو النسق الفيلمى؛

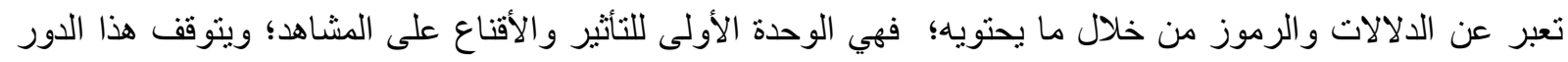
على حسن اختيار المكان و الزمان و الأبداع الفني في التصوير و الإخر اج و المونتاج وكلها عناصر تؤثر خاصدة اذاذا كانت

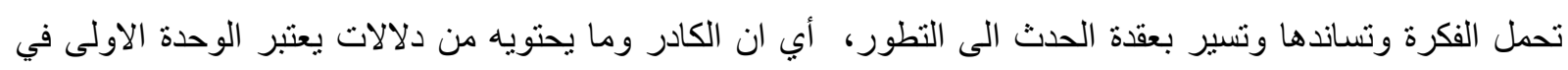

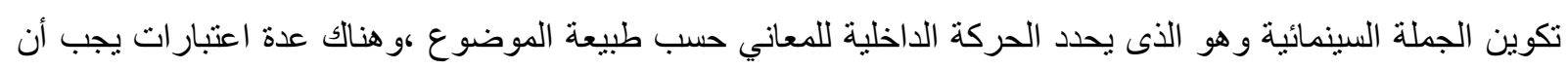
تؤخذ في الحسبان عند تكوين المشاهد المختلفة؛ وهى من العناصر المكونة للنص ومن العناصر التي تعطى للبنية الفيلمية منطقية في تتابع اللقطات و المشاهد المختلفة؛ هذه الاعتبارات ترتبط بمفهوم منطقة التكامل الحركي ، وتعنى بذللك ان ان المشاهد المتتالية يجب أن ترتب وفقا لرؤية المشاهد او المتفرج؛ أي انه اذا دخل شخص ما في الكادر من باب علئ على يمينه؛

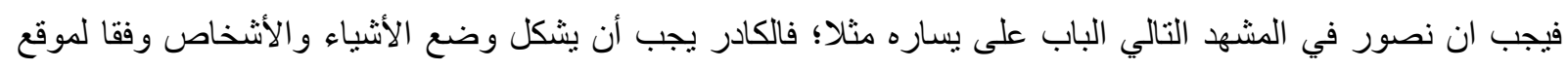
المشاهد أو المتفرج و اتجاه بصره، ويجب أن نعرف أن المحتويات الظاهرة في الكادر ليست لها القدرة على التعبير بمفردها؛ بل أن الأشياء الخارجة عن الحقل البصرى يمكن أن تعطى دلالات تأثيرية في نفس المشاهد.

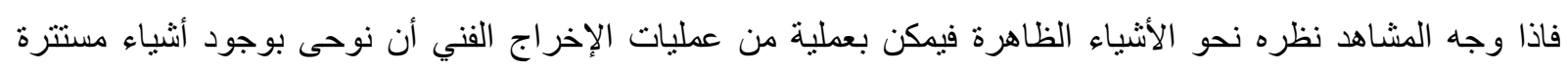

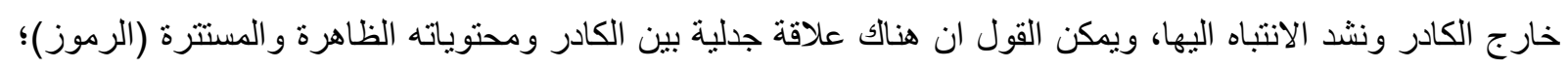
والمشاهد أي ان هناك حوار صامت بين المؤلف والمتلقي عبر الكادر ومحتوياته وطريقة إخراجه من الناحية الفنية

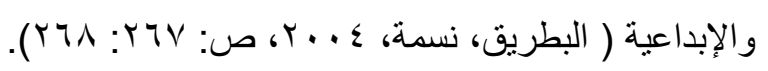
وكذللك فعنصر الفولكلور لها دور في ابراز قيم المجتمع وثقافته واختلافاته وذلك ما نم التعبير عنه في الفيلم من اظهار

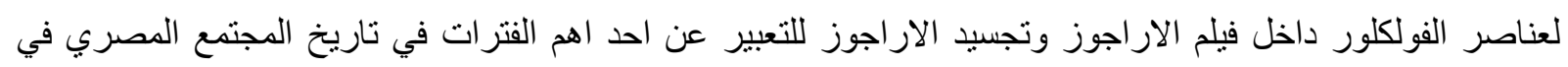
محاولة لدمج الو اقع بالخيال و الدراما بالتقنية لخلق لغة جديدة تحقق معانى اكثر امتاع وتركيز على مكنونات المجتمع .

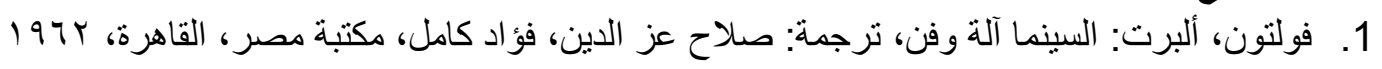
1. fultun , 'albirti: alsiynma alat wafan , tarjamatu: salah eiz aldiyn , fuad kamil , almaktabat almisriat, alqahirat, 1962.

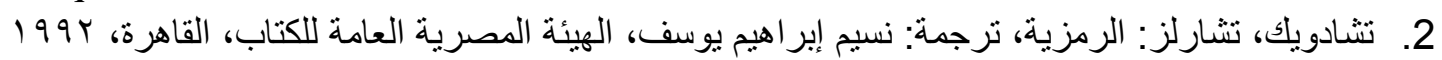
2. tshaduik, tsharliz: alramziat, tarjamatu: nasim 'iibrahim yusif , alhayyat aleamat lilkitab , alqahirat, 1992

3. أبو العلا، عصام: المسرحية العربية " الحقيقة التاريخية والزيف الفني، الهيئة المصرية العامة للكتاب، القاهرة،

$r . . v$

3. 'abu aleula , eisami: almasrahiat alearabia "alwaqayie walzayf alfaniyu , alhayyat aleamat lilkitab , alqahirat , 2007

4. الكامل، فرج: تأثثر وسائل الاتصال الأسس النفسية والاجتماعية، دار الفكر العربي الطبعة الأولى ، 1910 4. alkamil , faraj: tathir wasayil aliatisal al'usus alnafsiat waliajtimaeiat, dar alfikr alearabii altabeat al'uwlaa 1910。

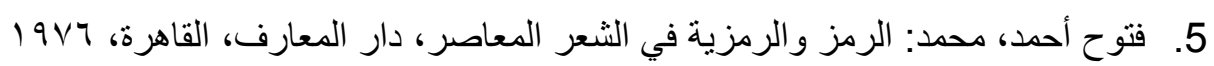

5. fatuh 'ahmad, muhamadu: alramz walramziat fi alshier almueasir , dar almaearif , alqahirat , 1976 
6. السويفى ، مختار : خيال الظل والعر ائس في العالم ، دار الكاتب العربي ، القاهرة ، VI97 6. alsuwayfaa , mukhtaru: khayal alzili walearayis fi alealam, dar alkatib alearabii , alqahirat, 1967

$$
\text { 7. حقي، مصطفى: التذوق الفني و السينما، دار غريب للطباعة، القاهرة، } 1990
$$

7. haqiy , mustafaa: altadhawuq alfaniyu walsiynima , dar gharib liltibaeat , alqahirat , 1995 8. محرم، مصطفى: مدخل إلى النقد السينمائي، المكتبة السينمائية، الهيئة المصرية العامة للكتاب، مكتبة الأسرة،

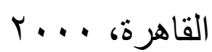

8. muharam , mustafaa: madkhal 'iilaa alnaqd alsiynamayiyi, almaktabat alsiynamayiyat , alhayyat almisriat aleamat lilkitab , maktabat al'usrat , alqahirat , 2000

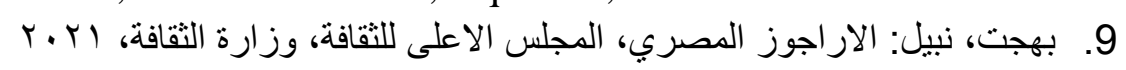

9. bahjat , nabil: alarajuz almisriu , almajlis alaelaa lilthaqafat , wizarat althaqafat , 2021

$$
\text { • اـ البطريق، نسمة: الدلالة في السينما والتليفزيون في عصر العولمة، دار غريب، القاهرة، ؟ ... }
$$

10- albatariq , nasamatu: aldilalat fi alsiynima waltilifizyun easr aleawlamat, dar gharib , alqahirat , 2004

ثانيا : المراجع الاجنبية

1- S, Dowining, and Bazargan: Image and Ideology in Modern Postmodern Discourse. N.Y.: Stat Univ. of N.Y. ,1991

2- B. Adams, William: Hand book of Motion Picture Production, Willy interscience Publication, New York 1977.

3- D., Hoffman, Visual intelligence, How we Create what we see, London, W.W.Norton Company, 1998.

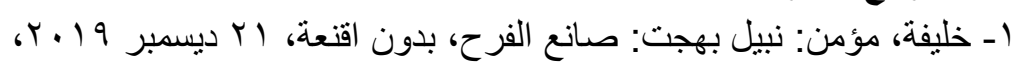
https://akhbarelyom.com/news/newdetails/2968538/1/\%D9\%86\%D8\%A8\%D9\%8A\%D9\%84 \%D8\%A8\%D9\%87\%D8\%AC\%D8\%AA-\%D8\%B5\%D8\%A7\%D9\%86\%D8\%B9-

\%D8\%A7\%D9\%84\%D9\%81\%D8\%B1\%D8\%AD

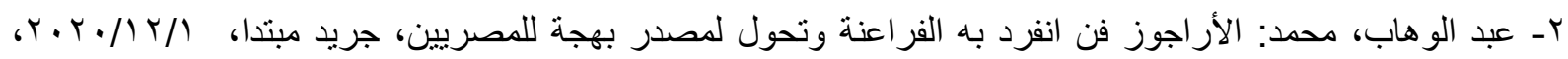
https://www.mobtada.com/details/993428

3 -httpllminerve.orglindex.php 